\title{
ACHIEVING ENVIRONMENTAL SUSTAINABILITY IN MYANMAR
}

David A. Raitzer, Jindra Nuella G. Samson, and Kee-Yung Nam

\section{No. 467 ADB ECONOMICS \\ December 2015 WORKING PAPER SERIES}


ADB Economics Working Paper Series

\section{Achieving Environmental Sustainability in Myanmar}

David A. Raitzer, Jindra Nuella G. Samson, and Kee-Yung Nam

No. 467 | December 2015
David A. Raitzer (draitzer@adb.org) is Economist, Jindra Nuella G. Samson (jsamson@adb.org) is Senior Economics Officer, and Kee-Yung Nam (kynam@adb.org) is Principal Economist at the Economic Research and Regional Cooperation Department, Asian Development Bank (ADB).

This paper was a background paper for the ADB

Myanmar Country Diagnostics Study. 
Asian Development Bank

6 ADB Avenue, Mandaluyong City

1550 Metro Manila, Philippines

www.adb.org

(C) 2015 by Asian Development Bank

December 2015

ISSN 2313-6537 (Print), 2313-6545 (e-ISSN)

Publication Stock No. WPS157803-2

The views expressed in this paper are those of the authors and do not necessarily reflect the views and policies of the Asian Development Bank (ADB) or its Board of Governors or the governments they represent.

ADB does not guarantee the accuracy of the data included in this publication and accepts no responsibility for any consequence of their use.

By making any designation of or reference to a particular territory or geographic area, or by using the term "country" in this document, $A D B$ does not intend to make any judgments as to the legal or other status of any territory or area.

Notes:

1. In this publication, " $\$$ " refers to US dollars.

2. ADB recognizes "Burma" as Myanmar and "China” as the People's Republic of China.

The ADB Economics Working Paper Series is a forum for stimulating discussion and eliciting feedback on ongoing and recently completed research and policy studies undertaken by the Asian Development Bank (ADB) staff, consultants, or resource persons. The series deals with key economic and development problems, particularly those facing the Asia and Pacific region; as well as conceptual, analytical, or methodological issues relating to project/program economic analysis, and statistical data and measurement. The series aims to enhance the knowledge on Asia's development and policy challenges; strengthen analytical rigor and quality of ADB's country partnership strategies, and its subregional and country operations; and improve the quality and availability of statistical data and development indicators for monitoring development effectiveness.

The ADB Economics Working Paper Series is a quick-disseminating, informal publication whose titles could subsequently be revised for publication as articles in professional journals or chapters in books. The series is maintained by the Economic Research and Regional Cooperation Department. 


\section{CONTENTS}

TABLES, FIGURES AND BOXES iv

ABSTRACT V v

$\begin{array}{ll}\text { I. INTRODUCTION } & 1\end{array}$

A. Overview 1

B. Objectives and Approach 1

C. Overall Measures of Environmental Performance 1

D. Environmental Performance Index Rating 2

E. Myanmar Environmental Performance Assessment 4

II. NATURAL RESOURCES MANAGEMENT

A. Forests and Mangroves 5

B. Wildlife 17

C. Water 18

D. Coastal and Fisheries 18

E. $\quad$ Climate Change May Amplify Degradation and Loss of Natural Resources 21

III. POLLUTION MANAGEMENT 23

A. Land/Waste $\quad 23$

B. Water 23

C. Air $\quad 24$

D. Greenhouse Gas Emissions 25

IV. POLICY MEASURES TO CONTAIN ENVIRONMENTAL DEGRADATION 26

A. Policy Framework $\quad 26$

B. Regulatory Processes $\quad 29$

C. Protected Areas 30

D. Safeguards $\quad 31$

E. Tenure $\quad 32$

F. Market Incentives $\quad 32$

V. CONCLUSIONS

$\begin{array}{ll}\text { REFERENCES } & 37\end{array}$ 


\section{TABLES, FIGURES, AND BOXES}

\section{TABLES}

$1 \quad$ Myanmar's Score on 2014 Environmental Performance Index and Rank Relative to 178 Other Countries 3

$2 \quad$ Ranking of Priority Environmental Concerns in Myanmar 4

3 Total and Closed Forest by State and Region, 1975-2010 6

$4 \quad$ Agribusiness Concessions Allocated in Myanmar 11

$5 \quad$ Transformation of Land Type Distribution in Myanmar, 1990-2011 12

6 Results of Fixed Effects Econometric Model of Deforestation Determinants in Myanmar under Three Alternative Model Specifications $\quad 16$

$7 \quad$ Inventory and Status of Identified Biodiversity in Myanmar 17

$8 \quad$ Fisheries Production in Myanmar, 2003-2013 19

9 Daily Average Air Quality in Yangon (2007) and Mandalay (2008) 25

10 Greenhouse Gas Emissions for Myanmar 26

11 Initial Result of Myanmar's National Greenhouse Gas Inventory, 201026

12 Major Environment-Related Policies and Laws in Myanmar 27

13 Myanmar's Membership in International and Regional Treaties 28

\section{FIGURES}

1. Indicator Framework of the 2014 Environmental Performance Index 2

2 Myanmar Forest Cover Change Compared with Southeast Asia and Bangladesh 6

3 Annual Wood Extraction in Myanmar $\quad 7$

4 Volume of Myanmar's Wood Exports $\quad 8$

$5 \quad$ Framework of Deforestation Determinants 13

6 Forest Loss Causes Implied by Coefficients Returned in Econometric Model Specification 2 of Table $6 \quad 17$

$7 \quad$ Fisheries Production in Myanmar, 2003-2013 19

8 Coastal Shelf Fishing Pressure in Southeast Asia, 1990-2006 20

9 Status and Progress of Marine Protection in the 2000s in Southeast Asia 20

$10 \quad$ Urban Air Pollution in Selected Cities in Southeast Asia 24

11 Sulfur Dioxide Emission per Capita in Southeast Asia 25

12 Terrestrial Protection Areas in Southeast Asia, 1990-2010 30

\section{BOXES}

1 Deforestation in Kachin State Border Area $\quad 9$

2 Myanmar's Vulnerability to Climate Change $\quad 21$

3 Increasing the Sustainability and Economic Contribution of Forest Resources 34 


\begin{abstract}
Myanmar's long isolation from international markets and sources of finance historically limited development, and thus, the pressure on its environment. Many of its resources remain relatively intact, despite an absence of effective environmental regulations. Yet, as the country integrates into the global economy and its economic development accelerates, resource degradation is rising rapidly. Deforestation of closed forests in recent years has taken place at the fastest rate among major Southeast Asian countries, much of it driven by concessions for plantations and other large-scale projects. Marine capture fishing pressure has increased rapidly, and the sustainability of catches is largely unknown. Water and air pollution effluents and emissions are escalating. At the same time, policy responses to date, while emphasizing overall sustainability, need to be developed to address these issues. Environmental impact assessment procedures, environmental quality standards, emissions regulations, and penalties for environmental violations remain under development. Perverse incentives for resource destruction are still in place and efforts to create market incentives for sustainable practices are at an initial stage. To ensure long-run, sustainable economic development, Myanmar's reforms need to address these issues more quickly and comprehensively.
\end{abstract}

Keywords: deforestation, environmental protection and conservation, Myanmar, pollution management, vulnerability to climate change

JEL Classification: O13, O44, Q15, Q56 


\section{INTRODUCTION}

\section{A. Overview}

Myanmar is endowed with rich natural resources and biodiversity, with $45 \%$ of land area as forests, a pristine coastline, and an exclusive economic zone that serves home to productive fisheries and other marine resources. However, despite these natural assets, Myanmar remains among the poorest nations in the world.

The country has relied heavily on natural resources to boost its economy, and to provide energy and livelihoods for its population. Natural resources sectors, such as forestry, agriculture, fisheries and mining have played critical roles in the development and economic transformation of the country, and over the years their operations have become more intensive and extractive. Serious environmental problems have emerged as a result, including deforestation, accelerated loss of rich biological diversity, and increased pollution (NCEA and UNEP 2008). According to international indices, environmental management in Myanmar now ranks among the world's lowest, and recent data reveal a rate of deforestation that is the highest among major Southeast Asian countries.

Although the country's main environmental policy statements (1994 Environmental Law and Agenda 21 commitments) embrace the goals of harmony and balance between environmental protection and economic growth, Myanmar has yet to take broader steps to protect its natural resources. Myanmar struggles to implement environmental protection and conservation protocols that meet international standards. The lack of a comprehensive and coordinated environmental framework, enabling institutional and legal structures, expertise, and greater capacity for natural resource management and funding remain challenges. Conservation of ecological wealth will depend on addressing perverse incentives for environmental degradation and ensuring that sound environmental policies, laws, and regulations are applied and enforced (ADB 2013).

Myanmar is at a critical crossroads. With many environmental assets, and industrial pressure only beginning to develop, it could effectively develop policies and regulations that ensure growth is sustainable and that key natural resources are conserved. At the same time, if appropriate action is not taken quickly, the future capacity of Myanmar's environment to sustain critical services will be diminished, threatening economic growth trajectories over longer periods.

\section{B. Objectives and Approach}

This working paper aims to identify current and future environmental problems in Myanmar, the pressures underpinning them, and the policy measures that can manage them. It begins by reviewing Myanmar's overall environmental status and areas of environmental concern noted in previous assessments. It then appraises these in greater detail to identify the present and potential drivers of degradation. In so doing, it focuses on deforestation, the primary environmental issue in Myanmar, for which econometric methods are applied to identify deforestation determinants. Finally, the paper appraises current policy measures for their ability to address the drivers of environmental degradation and makes policy recommendations.

\section{Overall Measures of Environmental Performance}

Myanmar benefits from many environmental assets, and low levels of environmental contamination to date. It has large areas of forest, abundant fisheries, low levels of waste generation, and few industries 
that generate pollution. Yet environmental degradation is rising, and an array of looming influences will increase environmental pressure.

\section{Environmental Performance Index Rating}

A widely recognized composite measure of countries' environmental management status, including Myanmar's, is the 2014 Environmental Performance Index (EPI), which was developed in an attempt to respond to the growing need for rigorous, data-driven environmental performance measurement to evaluate environmental sustainability of countries signatory to the Rio Earth Summit. The $2014 \mathrm{EPI}$ ranks 178 countries by their proximity to the targets for 19 performance indicators spanning nine policy categories under two overarching environmental objectives: environmental health and ecosystem vitality (Hsu et al. 2014, Figure 1).

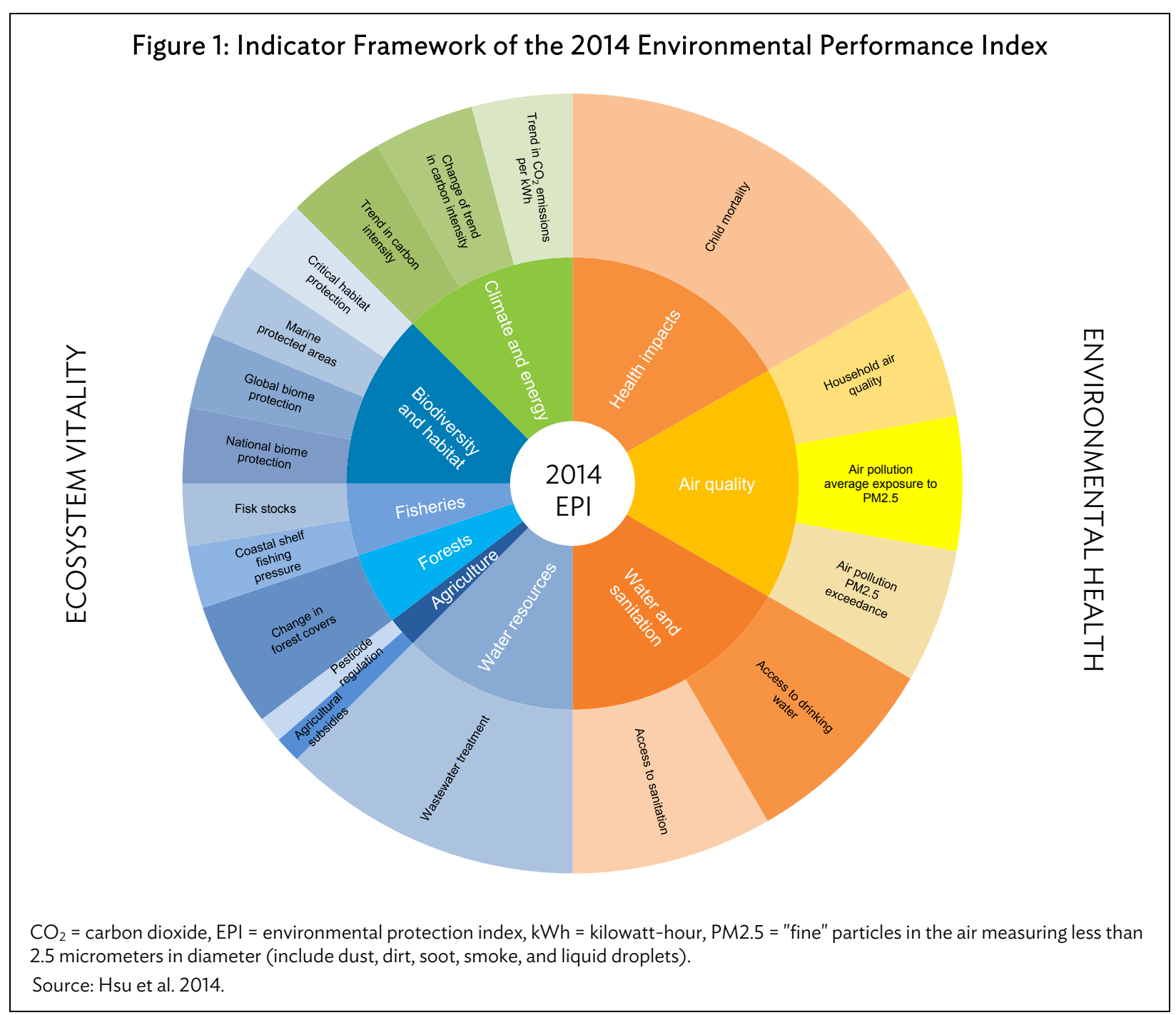

Each policy category consists of one or more environmental indicators. Following the EPI methodology, the environmental indicators composing the index are (i) normalized by proximity to policy targets (with 100 representing at or above the target and 0 representing farthest from the target), (ii) grouped into relevant policy categories, and (iii) aggregated into an overall index using weights. These 
indicators provide a picture of how close different jurisdictions are to established environmental policy goals. The proximity-to-target methodology facilitates comparisons between geographic entities (nations, regions) as well as analysis of how the country as a whole performs on each policy issue.

Myanmar ranks 164 out of 178 countries in the 2014 EPI, and is among the world's least developed in environmental management and regulation (Table 1). Almost every aspect of performance related to regulation or infrastructure has scores among the lowest globally. In addition, ecosystem vitality and protection of terrestrial biodiversity come out as particularly weak. ${ }^{\prime}$

\section{Table 1: Myanmar's Score on 2014 Environmental Performance Index and Rank Relative to 178 Other Countries}

\begin{tabular}{|c|c|c|}
\hline Indicator & Score & Rank \\
\hline EPIScore & 27.44 & 164 \\
\hline $10-$ Year\%change & 6.11 & 69 \\
\hline Environmental health & 41.39 & 137 \\
\hline Ecosystem vitality & 18.14 & 164 \\
\hline EH - Health impacts & 45.80 & 133 \\
\hline EH - Air quality & 47.68 & 171 \\
\hline $\mathrm{EH}-$ Water and sanitation & 30.69 & 116 \\
\hline EV - Water resources & 0.00 & 145 \\
\hline EV-Agriculture & 80.00 & 62 \\
\hline EV - Forests & 24.47 & 83 \\
\hline EV - Fisheries & 0.00 & 98 \\
\hline EV Biodiversity and habitat & 28.62 & 140 \\
\hline Child mortality & 45.80 & 133 \\
\hline Household air quality & 8.00 & 157 \\
\hline Air pollution - average exposure to PM2.5 & 78.56 & 151 \\
\hline Air pollution - average PM2.5 exceedance & 56.47 & 148 \\
\hline Access to sanitation & 29.11 & 104 \\
\hline Access to drinking water & 32.27 & 125 \\
\hline Wastewater treatment & 0.00 & 145 \\
\hline Agricultural subsidies & 100.00 & 1 \\
\hline Pesticide regulation & 60.00 & 121 \\
\hline Change in forest cover & 24.47 & 83 \\
\hline Fish stocks & 0.00 & 92 \\
\hline Coastal shelf fishing pressure & 0.00 & 95 \\
\hline Terrestrial protected areas (national biome weights) & 36.02 & 125 \\
\hline Terrestrial protected areas (global biome weights) & 25.86 & 134 \\
\hline Marine protected areas & 52.61 & 91 \\
\hline Critical habitat protection & 0.00 & 54 \\
\hline Access to electricity & 49.00 & 132 \\
\hline
\end{tabular}

$\mathrm{EH}=$ environmental health, $\mathrm{EPI}=$ environmental performance index, $\mathrm{EV}=$ ecosystem vitality, $\mathrm{PM} 2.5$ = "fine" particles in the air measuring less than 2.5 micrometers in diameter (include dust, dirt, soot, smoke, and liquid droplets).

Note: Some scores of 0 result from partial or unreliable data on the indicator.

Source: Hsu et al. 2014.

1 The 2014 EPI uses the satellite imagery derived forest cover dataset of Hansen et al. (2013) for its "change in forest cover" indicator. However, these estimates are not consistent with other estimates for Myanmar (as well as many other countries), and thus differ from the numbers used subsequently in this analysis. 


\section{E. Myanmar Environmental Performance Assessment}

For a more detailed understanding of environmental issues in Myanmar and to diagnose major environmental concerns, the Asian Development Bank and the United Nations Environment Programme funded the Environmental Performance Assessment. The National Coordinating Committee for that exercise identified seven principal environmental concerns in Myanmar (Table 2). Similar to the EPI's rating of below world average performance, forest management is a point of primary concern, as is biodiversity loss. In addition, issues related to air, water and land pollution/contamination are raised, which are consistent with low scores in the $2014 \mathrm{EPI}$.

\section{Table 2: Ranking of Priority Environmental Concerns in Myanmar}

\begin{tabular}{|c|c|c|}
\hline & Priority Environmental Concerns & Description of Concerns \\
\hline 1 & Forest resources & $\begin{array}{l}\text { Losses of forest vegetation, forest area, decline of forest } \\
\text { products, and forest services. }\end{array}$ \\
\hline \multirow[t]{2}{*}{2} & Water resources and quality status & $\begin{array}{l}\text { Declining surface and groundwater resources for human and } \\
\text { domestic consumption, and use of safe water. }\end{array}$ \\
\hline & & $\begin{array}{l}\text { Pollution of surface water bodies in urban and nonurban } \\
\text { areas. }\end{array}$ \\
\hline 3 & Land degradation & $\begin{array}{l}\text { Soil erosion, decline of soil fertility and increase of land } \\
\text { salinity. }\end{array}$ \\
\hline 4 & Climate change & Increased emission of greenhouse gases. \\
\hline 5 & Inadequate solid waste management & $\begin{array}{l}\text { Inadequate collection, disposal and management of solid } \\
\text { waste from household, municipal, and industrial premises. }\end{array}$ \\
\hline 6 & Threats to biodiversity & $\begin{array}{l}\text { Loss of habitat, fragile ecosystems, and extinction of plant } \\
\text { and animal species. Poaching, mining activities, and social } \\
\text { impacts. } \\
\text { Natural genetic resources. }\end{array}$ \\
\hline 7 & Impacts of mining industry on environment & $\begin{array}{l}\text { Land degradation, land contamination, surface and } \\
\text { underground water pollution, air pollution due to industrial } \\
\text { processes. }\end{array}$ \\
\hline
\end{tabular}

Source: National Commission for Environment al Affairs (NCEA) and United Nations Environment Programme (UNEP) Regional Resource Center for Asia and the Pacific 2008.

Taken together, the two assessments suggest an array of primary environmental problems in Myanmar, which can be considered in two classes: issues of natural resources management and issues of pollution/contamination. In the former, deforestation, biodiversity, fisheries, and water resources are identified, while in the latter, issues of land, water, and air pollution (including greenhouse gas emissions) are raised. The following sections explore each of these issues. 


\section{NATURAL RESOURCES MANAGEMENT}

\section{A. Forests and Mangroves}

Forested areas, which are public and formally under the ownership of the state, are important to maintaining Myanmar's ecological balance. They provide watershed protection, which prevents land degradation and recharges the country's water resources, and thus, supply water for domestic uses, agriculture, and power. Forest cover also conserves a vast range of biodiversity and is integral to carbon sinks for reducing atmospheric carbon dioxide. And for many ethnic communities, forests have cultural and spiritual values.

Forests provide important economic goods, such as timber, firewood and nontimber products important for livelihoods, as well as important environmental services. During insurgencies in the 1980s and the 1990s, the state relied heavily on the extraction of forest and mineral resources to generate funds for political and military undertakings. Forest logging, both legal and illegal, was massive and largely pursued under the control of the military during the 1990s and 2000s (Talbott, Waugh, and Batson 2012). Documented timber constituted about 6.7\% ( $\$ 594$ million) of the country's total export earnings in fiscal year (FY) 2010 (CSO 2012), while undocumented illegal timber exports may be four times higher than the documented value (UNODC 2013).

Myanmar historically has had a tradition of strong and sustainable forest management under the Myanmar Selection System. This System was introduced in 1856 for teak to ensure that selective harvesting was conducted at maximum sustained yields, based on the rate of forest biomass growth. The system also prescribed tending and thinning operations to maximize the sustained teak yield of the naturally regenerated forest. As such, Myanmar was a pioneer in applying scientific and sustainable principles to natural forest management.

Today, such management approaches have broken down. Myanmar's forest area declined from 39.7 million hectares in 1989 to 30.5 million hectares in 2010, with an average annual loss of 438,000 hectares of forest per year. This is an annual decline of $1.1 \%$, which accelerated to $1.9 \%$ between 2006 and 2010 (Figure 2). This is the fastest rate among major countries in South and Southeast Asia. The rate of forest degradation has been even faster, as the closed forest area fell $2.5 \%$ during 1989 to 2010 (Table 3). This too has worsened, as the rate grew to 3.1\% between 2006 and 2010. Not only are Myanmar's forests being rapidly lost, but this loss has been concentrated in the most dense and biologically important forest areas.

Different pressures have contributed to this deforestation, and some may be expected to increase: (i) commercial logging, (ii) plantation expansion, (iii) agricultural expansion, (iv) road construction/improved access, (v) fuelwood extraction, and (vi) hydropower and dams. The evidence and observations for each of these is reviewed in the next section, and then econometric analysis applied to determine their relative importance.

\section{Commercial Logging}

Unlike many developed countries, a majority of felled timber in Myanmar comes from felling of natural rather than planted forests. Private forest concessions have grown since the government opened the sector to more commercial logging ventures to maximize income for growth. Accordingly, official timber extraction volume has grown 5.9\% annually between FY2006 and FY2009 (Figure 3). 


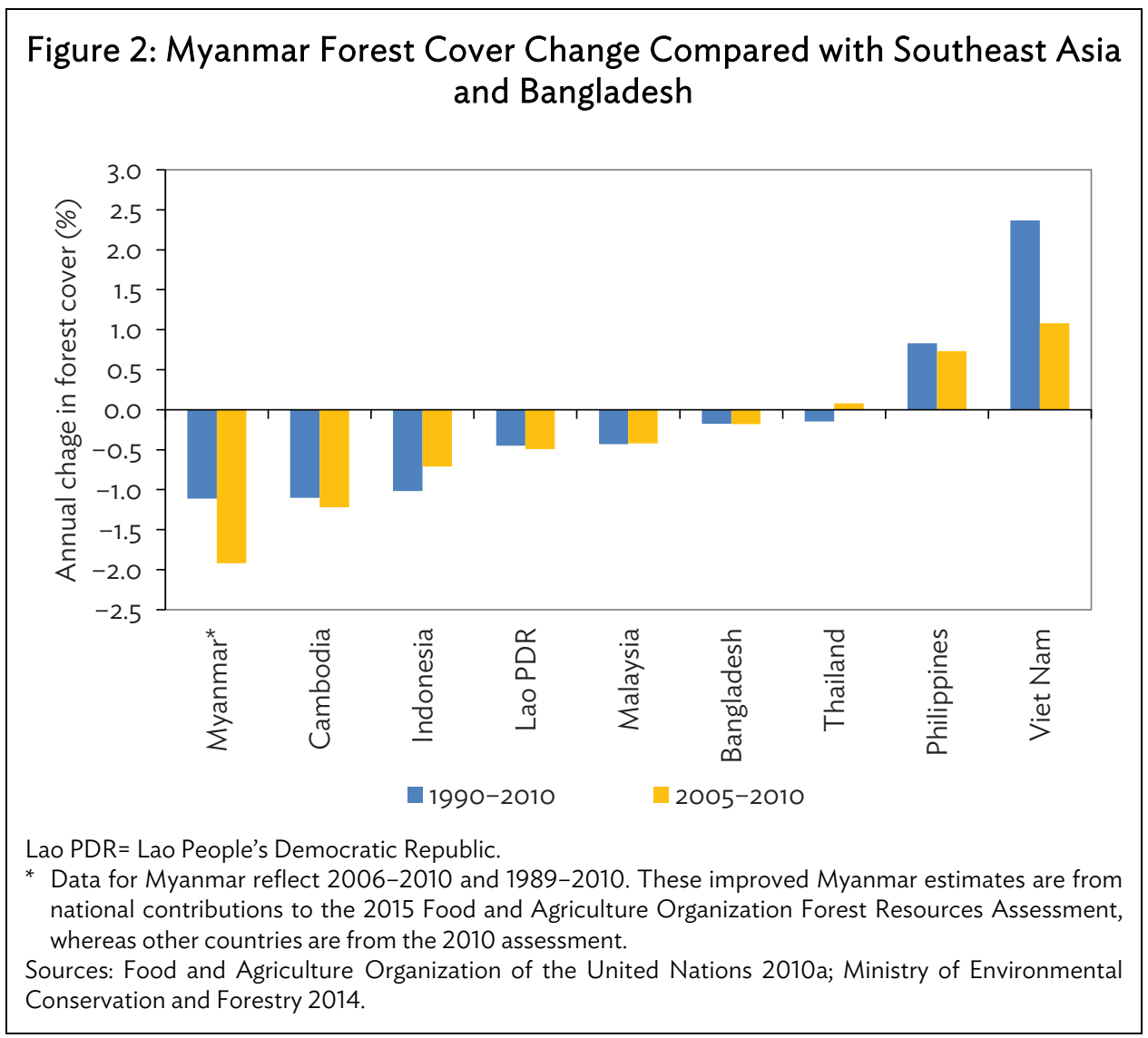

Table 3: Total and Closed Forest by State and Region, 1975-2010

\begin{tabular}{|c|c|c|c|c|c|c|c|c|c|c|c|c|c|}
\hline \multirow{3}{*}{$\begin{array}{l}\text { Area } \\
\text { State and } \\
\text { Division }\end{array}$} & \multirow{2}{*}{$\begin{array}{l}\text { Total } \\
\text { Land }\end{array}$} & \multicolumn{6}{|c|}{ Total Forested Area } & \multicolumn{6}{|c|}{ Closed Forest } \\
\hline & & & & & & & & & & & & & \\
\hline & & $\frac{1975}{7121}$ & $\frac{1989}{770}$ & 1997 & 1998 & 2006 & 2010 & $\frac{1975}{700}$ & 1989 & 1997 & 1998 & 2006 & 2010 \\
\hline Kacnin & 8 & 7,134 & 708 & 147 & 452 & 6 & 87 & 7,001 & 7,362 & 4,611 & ;382 & 4,819 & 4,675 \\
\hline Kayah & 1,173 & 824 & 689 & 753 & 753 & 437 & 44 & 578 & 435 & 520 & 520 & 130 & 160 \\
\hline Kayin & 3,038 & 1,837 & 1,751 & 2,439 & 2,281 & 2,044 & 1,409 & 1,433 & 1,429 & 1,208 & 1,088 & 1,151 & 576 \\
\hline Chin & 3602 & 2,488 & 2,419 & 2,337 & 2,336 & 2,329 & & 1,505 & 2,288 & 2,0 & 2,058 & 1,472 & 1,416 \\
\hline Sagain & 9,462 & 6,198 & 6,550 & 5,753 & 5,753 & 5,050 & 4,6 & 5,370 & 5,770 & 4,023 & 4,023 & 3,231 & 2,796 \\
\hline Tanintharyi & 4,335 & 3,651 & 3,739 & 3,520 & 3,733 & 3,411 & 2,9 & 3,021 & 3,408 & 2,717 & 2,751 & 2,480 & 1,890 \\
\hline Bago & 941 & 2,067 & 1,768 & 1,309 & 1,309 & 1,107 & 1 & 1,501 & 1,500 & 43 & 439 & 381 & 389 \\
\hline Magw & 4,48 & 2,577 & 1,688 & 1,044 & 1,044 & 6 & 80 & 709 & 01 & 68 & 687 & 546 & 562 \\
\hline Mandala & 3,702 & 1,416 & 1,297 & 716 & 716 & 913 & 71 & 879 & 684 & 493 & 493 & 124 & 182 \\
\hline Mon & 1,230 & 575 & 484 & 485 & 485 & 495 & 47 & 206 & 301 & 361 & 361 & 227 & 198 \\
\hline Rakhi & 3,678 & 2,416 & 2,316 & 1,765 & 1,765 & 2,477 & 2,16 & 1,921 & 2,058 & 1,211 & 1,211 & 831 & 495 \\
\hline Yang & 1 & 146 & 150 & 93 & 93 & 108 & 5 & 115 & 116 & 34 & 34 & 16 & 6 \\
\hline Shan & 15,580 & 8,796 & 8,277 & 7,593 & 8,344 & 7,411 & 6,319 & 5,540 & 5,209 & 6,709 & 7,246 & 1,940 & 1,848 \\
\hline Ayeya & & 1,071 & 853 & 423 & 423 & 401 & 4 & 545 & 494 & 224 & 224 & 120 & 113 \\
\hline Union total & 67,658 & 41,196 & 39,685 & 35,375 & 35,487 & 33,012 & 30,473 & 30,322 & 31,554 & 25,294 & 25,517 & 17,469 & 15,306 \\
\hline $\begin{array}{l}\text { Percent of } \\
\text { total land }\end{array}$ & & $61.0 \%$ & $59.0 \%$ & $52.0 \%$ & $52.0 \%$ & $48.8 \%$ & $45.0 \%$ & $45.0 \%$ & $47.0 \%$ & $37.0 \%$ & $38.0 \%$ & $25.8 \%$ & $22.6 \%$ \\
\hline
\end{tabular}

Source: Food and Agriculture Organization of the United Nations 2014. 


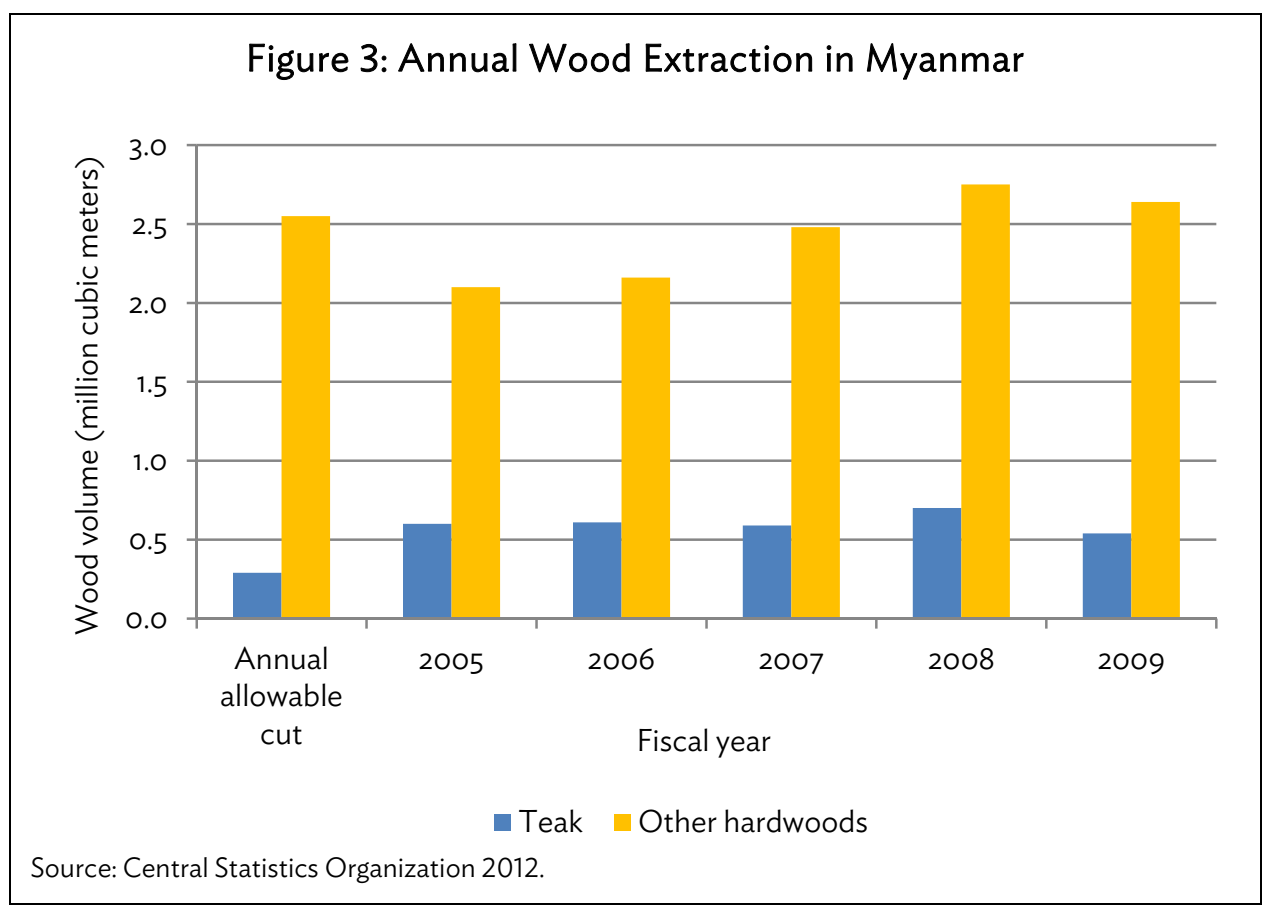

Clearly, these timber extraction values exceed those of teak, which has an annual allowable cut (AAC) of 0.29 million cubic meters $\left(\mathrm{m}^{3}\right)$, while the harvesting of other hardwoods in recent years also exceeded the annual allowable cut of 2.55 million $\mathrm{m}^{3}$. Accordingly, the volume of standing timber is falling. The top ten species with the highest share of timber volume fell from 1.34 billion $\mathrm{m}^{3}$ to 0.66 billion $\mathrm{m}^{3}$ from 1990 to 2000 . Only half (52\%) of production forest area has an explicit management plan (Woods and Canby 2011).

In 1993, the Government of Myanmar entirely banned private sector logging, meaning that all commercial logging is now undertaken under the auspices of the Myanmar Timber Enterprise (MTE), a commercial department of the Ministry of Environmental Conservation and Forestry (MOECAF). However, much of this logging is actually subcontracted to other companies, because the MTE has limited human resource capabilities and private sector logging concessions are operating in conjunction with the MTE. The MTE does not follow the Myanmar Selection System or the AAC, even though it is under MOECAF, as made clear in the statistics for teak extraction that exceed the AAC. Reportedly in the past, many logging concession operators have had military backgrounds or other connections to government officials, or have been offered concessions as payment for other services performed for the government (Woods and Canby 2011).

All legal timber in Myanmar must be shipped out of Yangon by boat. Exports via land borders are considered illegal, and are not considered part of official production statistics (Woods and Canby 2011). However, many concessions have been allocated in regions bordering the People's Republic of China (PRC) and Thailand, with substantial exports along land borders. It has been stated that as many as $80 \%$ of Myanmar's wood exports are illegal, and thus lack regulatory approvals (UNODC 2013). There is a clear discrepancy between official export volumes and the imports reported by the country's neighbors, suggesting that a large share of exports occur outside regulatory processes (Figure 4). 


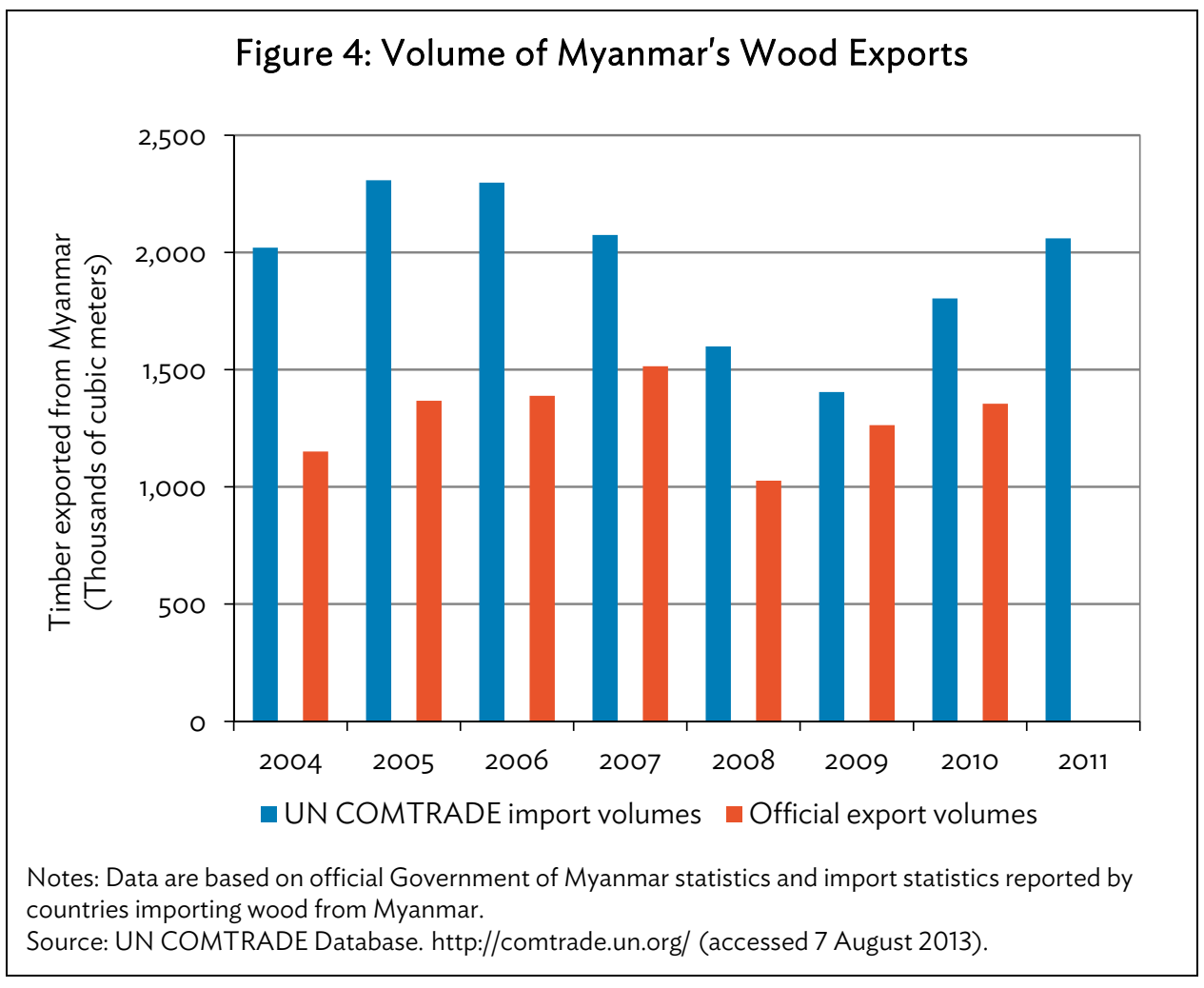

\section{Plantation Expansion}

Plantation area has rapidly expanded in Myanmar in recent years and now covers more than 2 million hectares. However, this expansion is small in comparison with the government's targets. In 2005, it decreed that it would develop eight million acres of jatropha biofuel plantations by 2010 and did not restrict plantation development to barren land (ECDF 2008). The project failed, but the specter of massive plantation development remains. 


\section{Box 1: Deforestation in Kachin State Border Area}

As background to the Food and Agriculture Organization's Myanmar 2020 Forestry Outlook study, land-use changes near the PRC-Kachin state border were quantified through the analysis of Landsat imagery from 1991 and 2005 (Than 2005). The results of that work (such as Box Figures 1.1 and 1.2) illustrate how plantation concession development leads to natural forest clearance, as it is evident in the maps that large-scale changes are emanating from the eastern border region, where there has reportedly been a plantation development as part of an opium substitution program from a neighboring country.

\section{Box Figure 1.1: 1991 Eastern Kachin State}

Land Cover Map of Eastern Kachin State (1991) (Landsat 5 TM 132-42
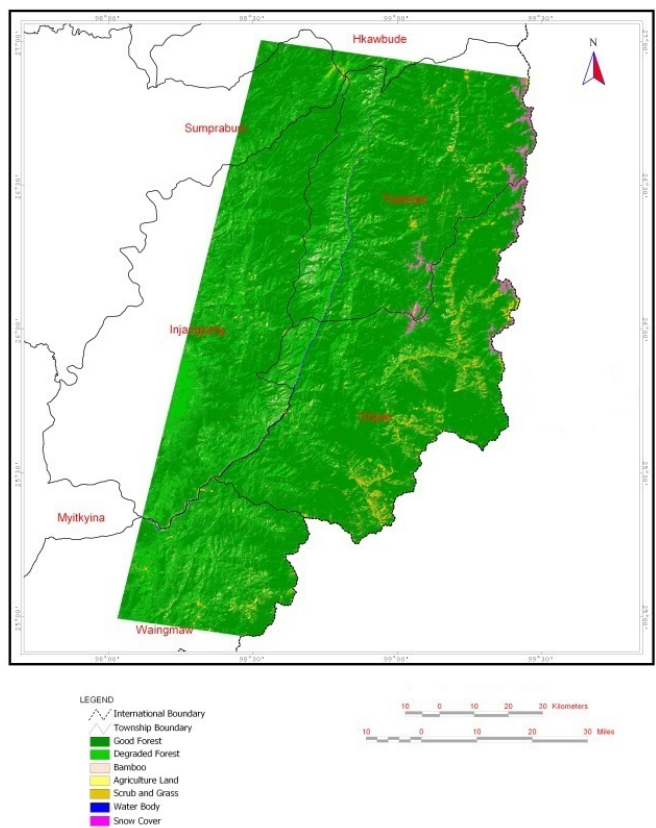

Box Figure 1.2: 2005 Eastern Kachin State

Land Cover Map of Eastern Kachin State (2005) (Landsat 7ETM+ 132-42)

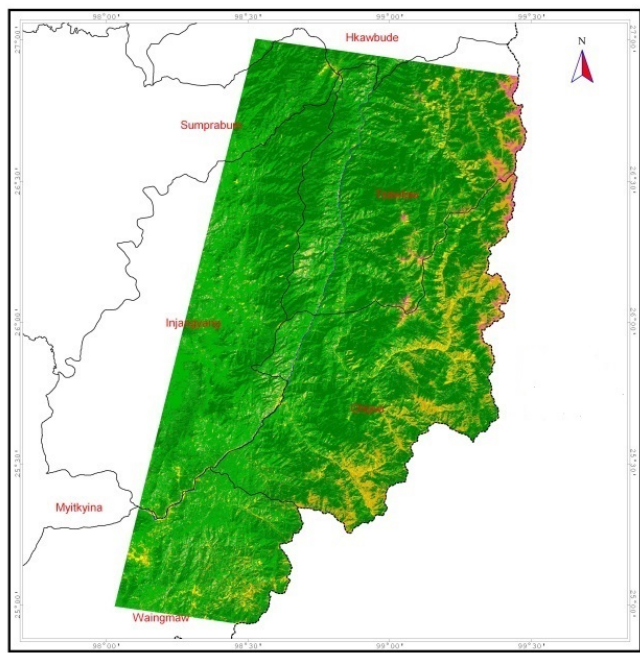

LGG6

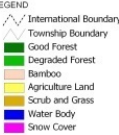

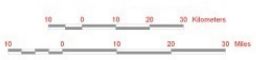

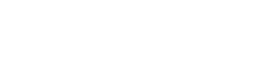

Sources: The left panel is from land-use map derived from Landsat 5tm 132-42 and the right from Landsat 7ETM+ 132-42.

The analysis also documented deforestation in the field. In the images gathered, it is clear that large tracts of mountain forest are being cleared for plantations of timber, rubber, and sugar cane (Box Figures 1.3-1.6).

Box Figure 1.3: Photo of Chinese Coffin Wood Plantations

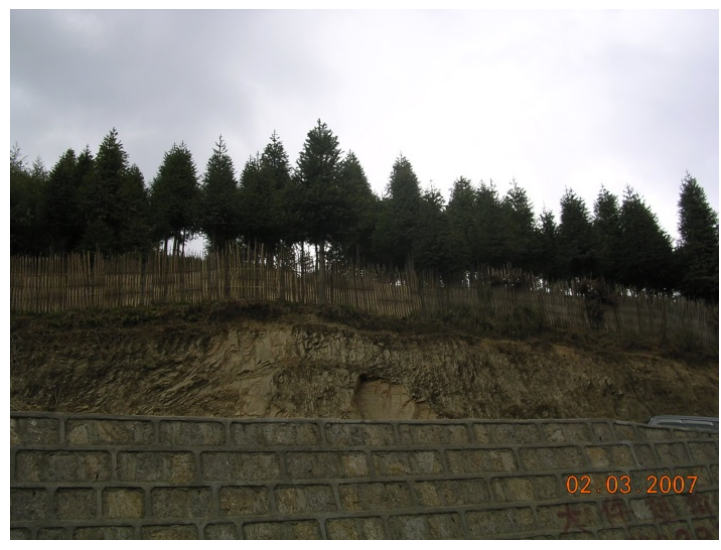

Box Figure 1.4: Photo of Forest Cleared for Rubber Plantations

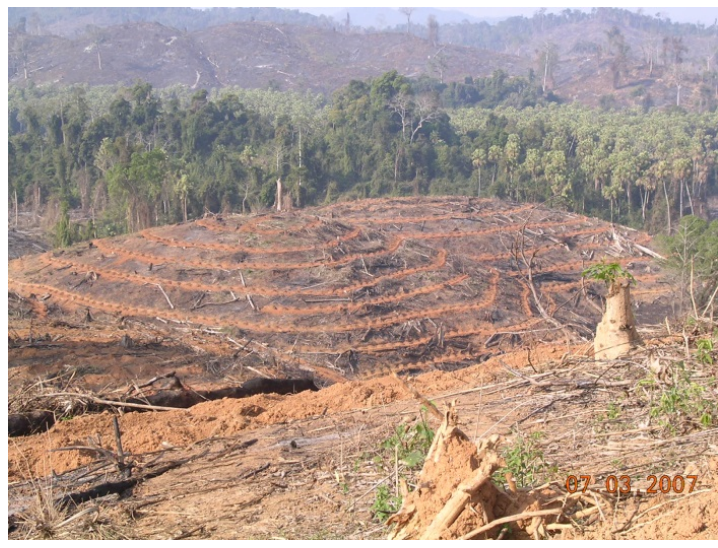


Box 1 continued

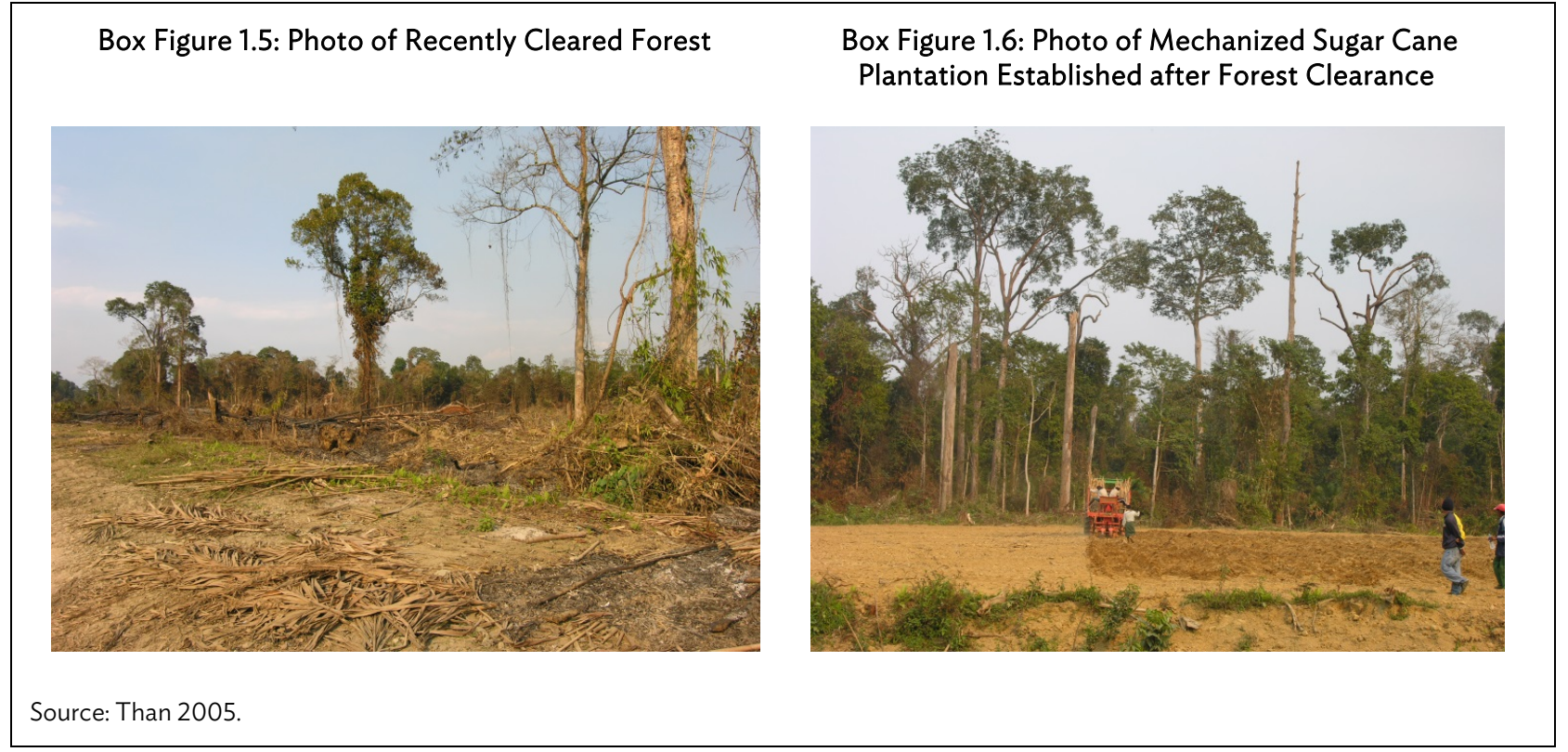

However, since 2010 most of the plantation development is associated with the private sector, and much is at a large scale. For example, 120,000 acres of rubber is reportedly under a foreignmanaged rubber concession in Rakhine State, a 200,000-acre cassava concession is under corporate management in Kachin State, and 1,000,000 acres of oil palm concessions is allocated to corporate interests (LRAN 2012). It has been reported that firms have received incentives for plantation development in border areas, under an opium substitution program from a neighboring country. Allocation of timber rich concessions, where minimal royalties will be collected on "conversion timber" clearly add to these incentives (see Box 1 and Woods 2013a).

Only $23 \%$ of allocated concession area is reportedly actually cultivated (Table 4). This suggests that concession allocation may not be driven by cultivation objectives. Concessions offer rents through the transfer of wood that can be cleared by concessionaires without paying full market value through royalties. In the absence of environmental impact assessment requirements to date, there is little to prevent concession allocation for obtaining these timber rents, which encourage deforestation.

\section{Agricultural Expansion}

A primary cause of deforestation across the tropical developing world is agricultural expansion, and Myanmar is no exception. This is consistent with forest transition theory, which suggests that as an economy begins to develop based on agricultural growth, agricultural land rent rises, increasing deforestation (Barbier, Burgess, and Grainger 2010). As an economy then develops and is structurally transformed, and nonagricultural growth surpasses agricultural growth, agricultural land rents begin to fall in relative terms. This is complemented by increased demand for forest services, as forests become scarcer and higher incomes lead to higher recreational demand, so that forest rents exceed those of agriculture, and forest cover increases. 
Table 4: Agribusiness Concessions Allocated in Myanmar

\begin{tabular}{|c|c|c|c|c|c|c|}
\hline & \multicolumn{3}{|c|}{ Allocated (acres) } & \multirow{2}{*}{$\begin{array}{c}\text { Concessions } \\
(\%)\end{array}$} & \multicolumn{2}{|c|}{ Planted by July 2013} \\
\hline & FY2010 & FY2011 & FY2012 & & (acres) & $(\%)$ \\
\hline Tanintharyi* & 671,594 & 993,887 & $1,896,970$ & 36.4 & 359,455 & 19.0 \\
\hline Kachin & 596,180 & $1,396,575$ & $1,381,165$ & 26.5 & 172,348 & 12.5 \\
\hline Sagaing & 100,057 & 259,273 & 533,406 & 10.2 & 19,543 & 3.7 \\
\hline Ayeyarwady & 193,353 & 285,844 & 335,331 & 6.4 & 212,969 & 63.5 \\
\hline Shan & 117,096 & 160,626 & 323,833 & 6.2 & 120,403 & 37.2 \\
\hline Magwe & 202,492 & 211,292 & 219,578 & 4.2 & 95,949 & 43.7 \\
\hline Bago & 19,772 & 52,238 & 200,150 & 3.8 & 91,074 & 45.5 \\
\hline Rakhine & $\ldots$ & 7,826 & 131,667 & 2.5 & 13,176 & 10.0 \\
\hline Yangon & 30,978 & 30,980 & 80,208 & 1.5 & 76,243 & 95.1 \\
\hline Mandalay & 10,300 & 6,262 & 56,046 & 1.1 & 14,497 & 25.9 \\
\hline Kayin & 2,161 & 4,011 & 34,946 & 0.7 & 15,867 & 45.4 \\
\hline Nay Pyi Taw & $\ldots$ & 7,408 & 17,554 & 0.3 & 5,217 & 29.7 \\
\hline Chin & $\ldots$ & 1,542 & 1,743 & 0.0 & 118 & 6.8 \\
\hline Kayah & $\ldots$ & $\ldots$ & $\ldots$ & $\ldots$ & $\ldots$ & $\ldots$ \\
\hline Mon & $\ldots$ & $\ldots$ & $\ldots$ & $\ldots$ & $\ldots$ & $\ldots$ \\
\hline TOTAL & $1,943,983$ & $3,417,762$ & $5,212,597$ & & $1,196,859$ & 23.0 \\
\hline
\end{tabular}

... = data not available, $\mathrm{FY}=$ fiscal year.

Source: Woods 2013b.

Myanmar is currently in the initial stage of this transition. Over the past 20 years, the physical proportion of its land area devoted to agriculture has risen $20 \%$, with increases in permanent crops accounting for half the expansion (Table 5). Even more pronounced is the 35\% increase in area of "other land," which is principally composed of "temporary crops." Together, the area increase of agricultural area and temporary cropped area, which was 7.73 million hectares between 1990 and 2011, almost exactly matches the forest area decline of 7.75 million hectares over the same period. ${ }^{2}$

\section{Road Construction/Improved Access}

Myanmar has a number of major road projects either planned or under construction, including the Bangkok-Daiwei road corridor, the northeastern linking highway to India, and highways linking Kalewa to Yargyi and Monywa. More broadly, kilometers of roads in Myanmar have been rising at 4.9\% annually from 1990 to 2010 (CSO 2012).

2 Note that the forest cover estimates in Table 6 are not consistent with Table 5, as they reflect FAOSTAT statistics, which are based on reporting by national statistical agencies, while the 2015 Forest Resources Assessment estimates are based on remote sensing with ground validation. 
Table 5: Transformation of Land Type Distribution in Myanmar, 1990-2011

\begin{tabular}{|c|c|c|c|c|c|c|c|}
\hline Land Type & $\begin{array}{c}1990 \\
\text { (thousand } \\
\text { hectares) }\end{array}$ & 2000 & 2005 & 2010 & 2011 & $\begin{array}{l}\text { 1990-2011 } \\
\text { (change, } \\
\text { thousand } \\
\text { hectares) }\end{array}$ & $\begin{array}{l}1990-2011 \\
\text { (\% change) }\end{array}$ \\
\hline Country area & 67,659 & 67,659 & 67,659 & 67,659 & 67,659 & & \\
\hline Land area & 65,354 & 65,354 & 65,336 & 65,326 & 65,329 & -25.0 & 0.0 \\
\hline Agricultural area & 10,428 & 10,812 & 11,263 & 12,526 & 12,558 & $2,130.0$ & 20.4 \\
\hline \multicolumn{8}{|l|}{ Arable land and permanent } \\
\hline $\begin{array}{l}\text { crops } \\
\text { Arable land }\end{array}$ & $\begin{array}{r}10,069 \\
9,567\end{array}$ & $\begin{array}{r}10,498 \\
9,909\end{array}$ & $\begin{array}{r}10,955 \\
10,059\end{array}$ & $\begin{array}{l}\mid 2,21 / \\
10,811\end{array}$ & $\begin{array}{l}12,250 \\
10,786\end{array}$ & $\begin{array}{l}2,181.0 \\
1,219.0\end{array}$ & $\begin{array}{l}21.7 \\
12.7\end{array}$ \\
\hline Permanent crops & 502 & 589 & 896 & 1,406 & 1,464 & 962.0 & 191.6 \\
\hline \multicolumn{8}{|l|}{ Permanent meadows and } \\
\hline Forest area & 39,218 & 34,868 & 33,321 & 31,773 & 31,463 & $-7,754.6$ & -19.8 \\
\hline Other land & 15,708 & 19,674 & 20,752 & 21,027 & 21,308 & $5,599.6$ & 35.6 \\
\hline Fallow land & & & 439 & 241 & 230 & & \\
\hline Temporary crops & & & 9,620 & 10,570 & 10,556 & & \\
\hline \multicolumn{8}{|l|}{ Total area equipped for } \\
\hline Irrigation & 1,056 & 1,868 & 2,136 & 2,329 & 2,292 & $1,236.0$ & 117.0 \\
\hline Inland water & 2,305 & 2,305 & 2,323 & 2,333 & 2,330 & 25.0 & 1.1 \\
\hline
\end{tabular}

Sources: Food and Agriculture Organization of the United Nations 2010b; Food and Agriculture Organization of the United Nations, FAOSTAT 2013. http://faostat.fao.org/site/630/default.aspx (accessed 7 August 2013).

More road infrastructure reduces transportation costs for forest timber and agricultural products, of which the latter becomes reflected in land values, according to the land rent framework first proposed by von Thünen (1826). This increase in cleared land and timber value boosts profits on forest encroachment and clearance, and increases deforestation. In accordance with this framework, road building and greater access to markets have been associated with deforestation in the Brazilian Amazon, Mexico, Cameroon, and elsewhere (Kaimowitz and Angelsen 1998). Similar effects may be anticipated in Myanmar.

\section{Fuelwood Extraction}

Forests remain the primary source of energy for most rural people and firewood is vital for their daily and domestic energy use. About $60 \%$ of national energy is derived from fuelwood (ADB 2012). This places great pressure on forest resources, and that pressure is rising: fuelwood rose from 18.6 million tons in 2000 to 23.2 million tons in 2009 (CSO 2012). To address this issue, the government has set a guideline to promote community fuelwood plantations, and targets to establish 2.27 million acres by 2030. However, only 0.11 million has been established since 1995 (BEWG 2011). This means that sustainable levels of production are stagnant, whereas extraction rates and overextraction are increasing.

\section{Hydropower and Dams}

Exploitation of Myanmar's huge hydropower potential has been limited to date. Forty hydropower dams with 3,000 megawatts (MW) of capacity have been built, but 88 more dams are planned, with a combined capacity of 14,000 additional MW. A number of these are large, with capacities over 1,000 MW individually (BEWG 2011). 
Dams can create pressure for deforestation when large areas of forest are flooded. Observations suggest that areas to be flooded by dam development have often been open to forest clearance by politically connected elites, with minimal royalties paid on cleared wood (McCoy 2007). This may create perverse incentives for locating dams in the most environmentally damaging areas.

\section{Empirical Analysis of Deforestation Determinants}

The discussion has so far identified potential causes of deforestation based on trends and observations described in various studies. To lend empirical evidence to the identification of proximate drivers of deforestation in Myanmar, a simple regression model is applied to identify the relative importance of the drivers discussed.

Analyses of the determinants of deforestation can generally be considered to be at one of three general levels. There are analyses of direct/proximate drivers of deforestation, which assess the relationships between the actions of particular agents (farmers, fuelwood collectors, plantation developers, commercial loggers, and so on) and deforestation outcomes. At the next level are analyses of intermediate factors that condition agent choices, so as to indirectly affect deforestation (often factors that directly affect returns to competing land use and forest product extraction, such as technologies, markets and subsidies). At the highest level are analyses of the macro variables that condition intermediate factors, such as economic growth and trade policies. While understanding at all levels is important for comprehensive policy solutions to deforestation, higher level analyses require understanding at the lower levels. Moreover, variability in the independent variables that can be exploited for econometric analysis can often be found only across larger spatial scales for the higher level analyses, as conditioning policies are often implemented at national levels. This means that the initial point for investigation of drivers of deforestation within a single country, such as Myanmar, should be the proximate/direct level (Figure 5). It is to this end that the econometric effort of this paper is directed.

Figure 5: Framework of Deforestation Determinants

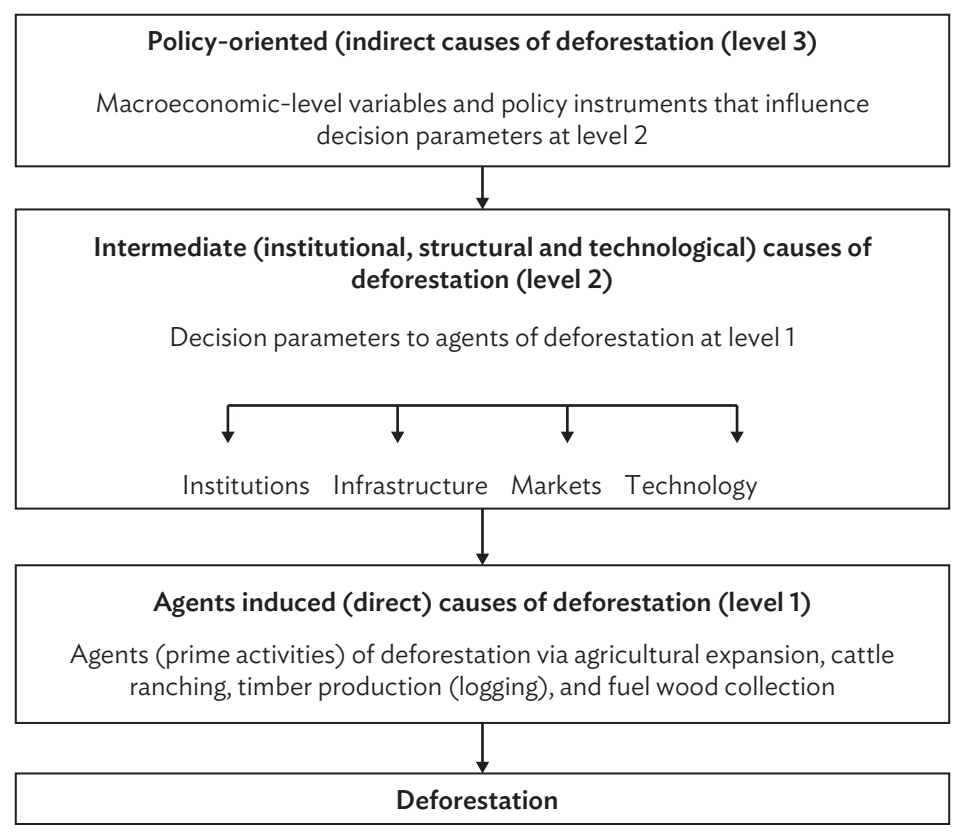

Source: Culas and Dutta (2003), adapted from Kaimowitz and Angelsen (1998). 
The regression approach employed utilizes observations at the region/state level at multiple points in time to associate proximate causes with forest cover change. These panel observations are employed in a one-way fixed effects regression design, which allows for time-invariant factors to be eliminated from the regression model. This is advantageous because the initial values in the dataset for independent variables and forest cover vary greatly across the regions/states, and the effects of this initial cross-sectional variability can hence be eliminated, such that only changes in the independent variable values over time are associated with changes in forest cover over time. This reduces omitted variable bias.

The dependent variable for the model is area of "closed forest," where closed forest is considered as a proxy for primary or high conservation value forests. The data source is a new set of 2010 region/state level observations generated by the Myanmar Ministry of Environmental Conservation and Forestry for the 2015 Food and Agriculture (FAO) Forest Resources Assessment, along with observations generated for the 2010 Forest Resources Assessment. These observations are generated using LANDSAT 7 ETM imagery, with ground verification by MOECAF personnel. Such data are unique, as other global and regional remote sensing derived estimates of forest cover for Myanmar use algorithms for image classification that are not well suited to the country's tropical dry forest cover and are not field validated. However, the Forest Resources Assessment data are derived from algorithms that are Myanmar-specific and validated. These data are available for 2006 and 2010, hence the regression is carried out for 14 subnational units over the two periods (although some variables are sums of observations over multiple years, as noted below).

The independent variables in the model are secondary statistics reported at the region/state level by the Central Statistical Office. These include reported extracted volumes of teak, hardwood, annual cropped area, length of improved (surfaced) roads, and rural population. Rural population is included as a proxy for fuelwood pressure, given the dominance of fuelwood in all rural energy supplies. Installed hydropower capacity has been approximated based on installed capacity reported per project and summed across projects at various points in time. The area of agricultural concessions by state is taken from reports by Woods (2013b) for 2010 and is approximated for 2006 based on Woods (2013a).

Adjustments were performed to address temporal issues in the data. Differences in forest cover between 2006 and 2010 due to logging and other timber extraction may arise not only from extraction in 2010, but also due to extraction in other years between the time periods. To address this, logging values for the two prior years to the year of observation were added to the observation year for extracted teak and hardwood. Similarly, land conversion and facilities construction for large-scale hydropower often takes place over a decade or more, such that deforestation effects, which principally occur during initial construction phases, may be years prior to hydropower capacity coming online. For this reason, hydropower values are advanced by 7 years in the regression, relative to the initial capacity utilization. For ongoing projects, initial capacity utilization dates were based on plans.

Myanmar has a relatively weak statistical system, with data that may conflict with estimates by outside bodies, and some values that may appear to be interpolated over space or time. In an attempt to reduce this threat to validity, trends in the data used were checked to ensure that they were not perfectly linear and that trends differed by location. However, data quality does remain a limitation to the analysis and the results should be interpreted with some caution. 
The regression is attempted with a series of three alternative model specifications, starting with a simple version, and including additional independent variables in two subsequent variants. They are presented in equations 1 through 3 . The simplest model (equation 1) treats forest cover as a function of teak and hardwood extraction, plus a region/state specific intercept. Next, equation 2 considers agribusiness concession area as an additional source of forest cover change, as "conversion timber" removals may not be reflected in statistics on official logging, particularly if exported over land borders illegally. Equation 3 adds other deforestation causes, such as hydropower dam development, agricultural expansion, and factors that may facilitate (improved roads) or drive (rural population) intensified smallholder forest extraction.

Equation 1:

$$
\begin{gathered}
F_{i t}=\alpha_{i t}+\beta_{1}\left(T_{E A K_{i t}}+T E A K_{i t-1}+T E A K_{i t-2}\right)+\beta_{2}\left(\text { HARDWOOD }_{i t}+\text { HARDWOOD }_{i t-1}\right. \\
\left.+ \text { HARDWOOD }_{i t-2}\right)+\varepsilon_{i t}
\end{gathered}
$$

Equation 2:

$$
\begin{gathered}
\text { FOR }_{i t}=\alpha_{i t}+ \\
\beta_{1}\left(\text { TEAK }_{i t}+\text { TEAK }_{i t-1}+\text { TEAK }_{i t-2}\right)+\beta_{2}\left(\text { HARDWOOD }_{i t}+\text { HARDWOOD }_{i t-1}\right. \\
\left.+ \text { HARDWOOD }_{i t-2}\right)+\beta_{3} \text { CONCESSION }_{i t}+\varepsilon_{i t}
\end{gathered}
$$

Equation 3:

$$
\begin{aligned}
\text { FOR }_{i t}=\alpha_{i t}+ & \beta_{1}\left(\text { TEAK }_{i t}+\text { TEAK }_{i t-1}+\right.\text { TEAK } \\
& \left.+ \text { HARDWOOD }_{i t-2}\right)+\beta_{2}\left(\text { HARDWOOD }_{3}+\text { CONCESSION }_{i t}+\beta_{4} \text { CROPS }_{i t}+\beta_{5} \text { POPDWOOOODION }_{i t-1}\right. \\
& +\beta_{6} \text { ROADS }_{i t}+\beta_{7} \text { HYDRO }_{i t+7}+\varepsilon_{i t}
\end{aligned}
$$

Where:

FOR = area of closed forest (hectares)

$\alpha=$ region/state specific intercept

TEAK = volume of teak logged (cubic meters)

HARDWOOD = volume of other hardwoods logged (cubic meters)

CONCESSION = area of agribusiness concessions (hectares)

CROPS = area of annual crops (hectares)

POPULATION = rural population (thousands of people)

ROAD = length of improved/surfaced roads (kilometers)

HYDRO = installed hydropower capacity (megawatts)

$\varepsilon=$ error term

Table 6 presents results of the regression. Model 1 is significant and finds that hardwood overextraction is a significant (negative) driver of closed forest cover, while teak extraction has no significant effect at observed levels. However, model 2 substantially improves upon the explanatory power of the regression by adding agribusiness concession area, which comes out as a highly significant driver of lower forest cover levels. Moreover, the coefficient suggests that each hectare of concession area is associated with 1.6 hectares of lower closed forest cover-an effect that is more than proportional. Model 3 illustrates that independent variables related to the activities of farmers and rural populations are not individually significant, and neither is the effect of hydropower development projects to date. Significant coefficients from model 2 are stable in model 3, while the R-squared is little improved. This suggests that model 2 represents the best combination of model parsimony and explanatory power. 
Table 6: Results of Fixed Effects Econometric Model of Deforestation Determinants in Myanmar under Three Alternative Model Specifications

\begin{tabular}{|c|c|c|c|}
\hline & 1 & 2 & 3 \\
\hline & $\begin{array}{c}\text { Closed Forest Area } \\
\text { (hectares) }\end{array}$ & $\begin{array}{c}\text { Closed Forest Area } \\
\text { (hectares) }\end{array}$ & $\begin{array}{c}\text { Closed Forest Area } \\
\text { (hectares) }\end{array}$ \\
\hline \multirow{2}{*}{$\begin{array}{l}\text { Hardwood extraction } \\
\text { (cubic meters) }\end{array}$} & -0.570 & -0.428 & -0.573 \\
\hline & $(0.144)^{* * *}$ & $(0.161)^{* *}$ & $(0.261)^{* *}$ \\
\hline \multirow[t]{2}{*}{ Teak extraction (cubic meters) } & 0.241 & 0.311 & -0.352 \\
\hline & $(0.813)$ & $(0.797)$ & $(1.211)$ \\
\hline \multirow[t]{2}{*}{ Concession area (hectares) } & & -1.604 & -1.616 \\
\hline & & $(0.489)^{* * *}$ & $(0.548)^{* *}$ \\
\hline \multirow[t]{2}{*}{ Annual crop area (hectares) } & & & 0.158 \\
\hline & & & $(1.172)$ \\
\hline \multirow{2}{*}{ Rural population (thousands) } & & & -274.147 \\
\hline & & & $(590.695)$ \\
\hline \multirow[t]{2}{*}{ Length of improved road (kilometers) } & & & 877.258 \\
\hline & & & $(1,035.282)$ \\
\hline \multirow[t]{2}{*}{ Hydropower capacity (megawatts) } & & & 10.068 \\
\hline & & & $(10.789)$ \\
\hline \multirow[t]{2}{*}{ Constant } & $1,325,854.213$ & $1,328,671.982$ & $1,858,135.396$ \\
\hline & $(72,806.506)^{* * *}$ & $(76,026.130)^{* * *}$ & $(1,069,741.505)$ \\
\hline$R^{2}$ & 0.16 & 0.45 & 0.48 \\
\hline $\mathrm{N}$ & 28 & 28 & 28 \\
\hline
\end{tabular}

${ }^{*} p<0.1 ;{ }^{* *} p<0.05 ; * * * 0.01$

Source: Authors' estimates.

The implications of the significant coefficients from model 2 are that agribusiness concessions have been associated with the approximately 1.13 million hectares less closed forest in Myanmar from 2006 to 2010, while over logging has been associated with 254,000 hectares less forest cover. Considering that 2.16 million hectares of closed forest were lost over the period, this means that concession allocation may have been responsible for more than half of this loss (Figure 6). This means that improving safeguard processes for concession allocation and ensuring that there are no economic incentives for forest clearance in concession areas are likely to be essential to reducing deforestation and forest degradation. 
Figure 6: Forest Loss Causes Implied by Coefficients Returned in Econometric Model Specification 2 of Table 6

(\%)

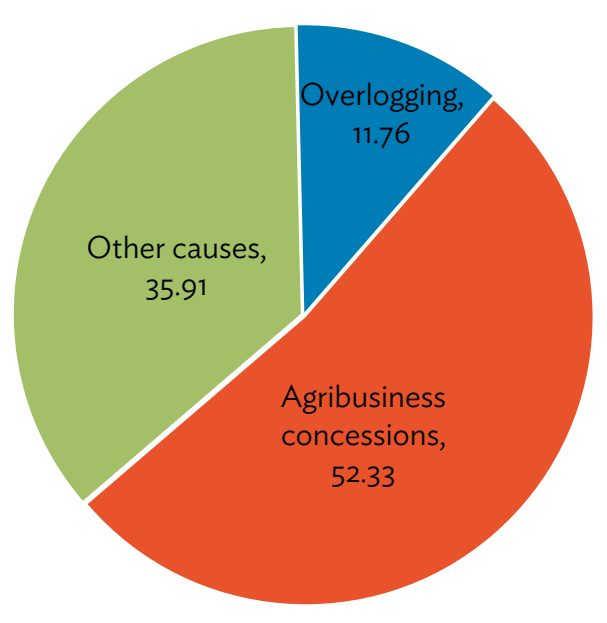

Source: Authors' estimates.

\section{B. Wildlife}

Myanmar is known as "the last frontier" of biodiversity in Asia due to its rich natural resource endowments and high diversity of flora and fauna (BEWG 2011) (Table 7). Its fauna includes 252 species of mammals, 1,056 of birds, 295 of reptiles, 775 of fish, and 119 of amphibians (Table 7).

Table 7: Inventory and Status of Identified Biodiversity in Myanmar

\begin{tabular}{lcc}
\hline Taxa & Number of Species & Number of Threatened Species \\
\hline Vertebrates & & \\
Amphibians & 119 & 0 \\
Birds & 1,056 & 44 \\
Fishes & 775 & 40 \\
Mammals & 252 & 46 \\
Reptiles & 295 & 29 \\
Invertebrates & & \\
Mollusks & $\ldots$ & 3 \\
Other invertebrates & $\ldots$ & 74 \\
Plants & 11,824 & 47 \\
\hline Total & 14,321 & 283 \\
\hline
\end{tabular}

... = data not available.

Source: Number of species is from the Ministry of Environmental Conservation and Forestry (2014) and the number of threatened species is from the International Union for the Conservation of Nature (2014).

The effects of habitat loss through deforestation and land-use change are compounded by the effects of wildlife capture on biodiversity. Myanmar has enacted regulations against the capture of wildlife with the Protection of Wildlife and Wild Plants and Conservation of Natural Areas Law of 1994 and with the signing of the Convention on the International Trade of Endangered Species (CITES) international treaty in 1973. Even so, poaching remains common. Its neighbor, the PRC, has been 
observed as a large market for products from flagship forest animal species, such as tigers and leopards (Oswell 2010). Meanwhile, border areas often are not under effective government control due to the presence of armed insurgent groups. As a result, enforcement of restrictions on wildlife capture and poaching is often limited, while the potential value of captured animals is high. This creates incentives for widespread wildlife capture. Accordingly, as one example, TRAFFIC, the wildlife trade monitoring network, observed more than 400 tigers for sale dead and alive during the 2000s (Oswell 2010), and this is probably just a small share of the total wildlife trade.

\section{Water}

Myanmar's water resources are abundant but water demands are rising and hydropower development may restrict future water availability. The catchment area, where 10 of the country's principal river channels meet, is estimated to be about 737,800 square kilometers $\left(\mathrm{km}^{2}\right)$, while total available internal annual renewable water resources for the country are estimated at 1,003 cubic kilometers (FAO, AQUASTAT 2013). Sectoral withdrawal of freshwater resources is estimated at $7 \%$ for domestic use, $3 \%$ for industrial, and $90 \%$ for agriculture use. As irrigation infrastructure is developed, consumption by agriculture, the major source of withdrawals, is expected to increase.

A primary constraint to future water resources availability is dam development, particularly for hydropower. From 1990 to 2009, the country constructed 252 dams and reservoirs for irrigation and flood protection. An estimated 88 hydropower projects are currently proposed, constructed, or already existing on major rivers, including the Salween/Thanlwin, Irrawaddy (or Ayeyarwady), Chindwin, and Sittaung (BEWG 2011).

Dam development may physically constrict downstream water availability and it can reduce the environmental services offered by river systems. For example, nutrient supplies mobilized through silt and sediment deposition may be reduced or eliminated, while fish migration and spawning habitat may be impeded. Currently, such effects have limited consideration in Myanmar's dam designs, as environmental impact assessment procedures are not yet approved.

\section{Coastal and Fisheries}

Overall fisheries catches have risen dramatically since the late 1990s. From FY2003 to FY2012 fisheries production rapidly rose at an annual average rate of $11 \%$, based on increased growth in aquaculture and capture fisheries production (Figure 7). A major reason for the boom in the fishery industry is the increase in foreign demand for Myanmar's fish products. Between 1990 and 2009, exports grew from 9.3 thousand tons to 464 thousand tons (Table 8, FAO, AQUASTAT 2013). It is not clear whether Myanmar's capture fisheries can sustain such massive growth in catches, as sustainable catch estimates have not been updated since the 1970s. Moreover, Myanmar's protected fisheries areas are miniscule, at $0.22 \%$ of marine area.

In 1990, the Marine Fisheries Law was passed to promote inland fish and prawn production, which has also led to the rise of many processing industries, and substitutes for capture fisheries. However, this also creates land-use competition and in-land water pollution, which may in turn affect freshwater resources and conversion of productive agricultural lands (Min Htut Yin 2011). As of 2006, $30 \%$ of species in Myanmar's terrestrial seas and exclusive economic zones are overexploited or have collapsed due to fishing, which is lower than many other countries in the subregion (University of British Columbia Fisheries Centre and the PEW Charitable Trusts 2011). 


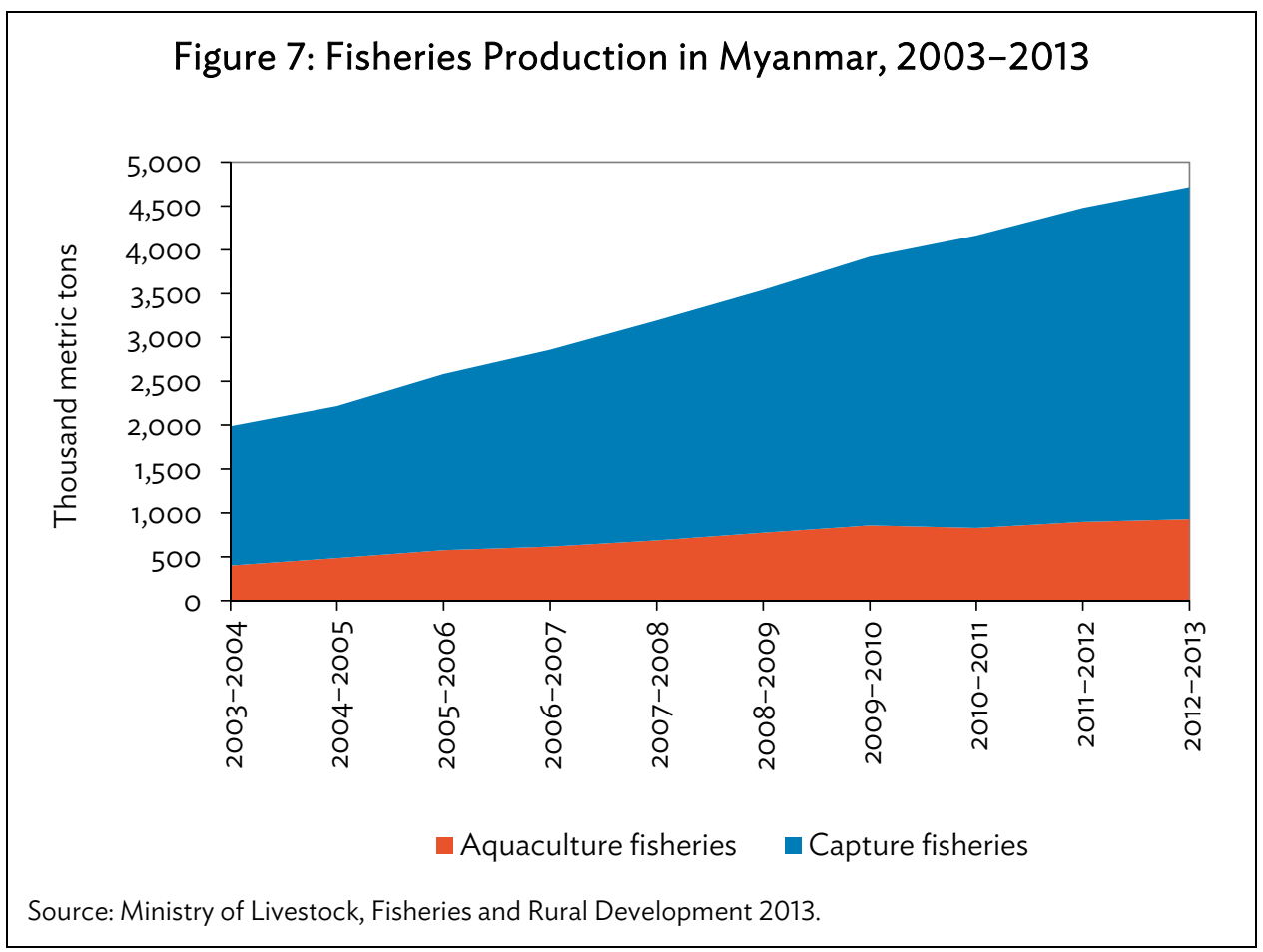

Table 8: Fisheries Production in Myanmar, 2003-2013 (thousand metric tons)

\begin{tabular}{lcccccc}
\hline Year & $\begin{array}{c}\text { Total } \\
\text { Production }\end{array}$ & $\begin{array}{c}\text { Aquaculture } \\
\text { Fisheries }\end{array}$ & $\begin{array}{c}\text { Leasable } \\
\text { Fisheries }\end{array}$ & $\begin{array}{c}\text { Open } \\
\text { Fisheries }\end{array}$ & $\begin{array}{c}\text { Marine } \\
\text { Fisheries }\end{array}$ & $\begin{array}{c}\text { Exports } \\
(\$ \text { million })\end{array}$ \\
\hline $2003-2004$ & $1,986.9$ & 400.4 & 122.3 & 331.9 & $1,132.3$ & 166.9 \\
$2004-2005$ & $2,217.8$ & 485.2 & 136.8 & 366.8 & $1,228.7$ & 189.7 \\
$2005-2006$ & $2,581.8$ & 574.9 & 152.7 & 478.4 & $1,375.7$ & 271.4 \\
$2006-2007$ & $2,859.9$ & 616.5 & 170.1 & 548.1 & $15,525.3$ & 468.2 \\
$2007-2008$ & $3,193.9$ & 687.7 & 191.1 & 625.4 & $1,689.8$ & 561.0 \\
$2008-2009$ & $3,542.2$ & 775.2 & 209.7 & 689.7 & $1,867.5$ & 483.2 \\
$2009-2010$ & $3,921.9$ & 858.8 & 237.4 & 764.9 & $2,060.8$ & 496.6 \\
$2010-2011$ & $4,163.5$ & 830.5 & 250.0 & 913.1 & $2,169.8$ & 555.5 \\
$2011-2012$ & $4,478.2$ & 898.9 & 282.6 & 963.8 & $2,332.8$ & 653.8 \\
$2012-2013$ & $4,716.2$ & 929.4 & 290.0 & $1,012.9$ & $2,483.9$ & 652.8 \\
\hline
\end{tabular}

Source: Ministry of Livestock, Fisheries and Rural Development 2013.

Myanmar's continued primary use of low-impact traditional fishing methods has helped to keep fisheries catches from booming even more rapidly. In terms of fishing at coastal shelves using trawling and dredging gear, Myanmar has remained less intensive than its neighbors and has even improved in the 2000s. About 0.10 tons per square kilometer $\left(\mathrm{t} / \mathrm{km}^{2}\right)$ of the catch in the exclusive economic zones in 2006 were associated with trawling and dredging (Figure 8), the lowest in the region. Catches associated with trawling and dredging decreased from $0.14 \mathrm{t} / \mathrm{km}^{2}$ in 1990 to a low $0.10 \mathrm{t} / \mathrm{km}^{2}$ in 2000 and 2006. 
Figure 8: Coastal Shelf Fishing Pressure in Southeast Asia, 1990-2006

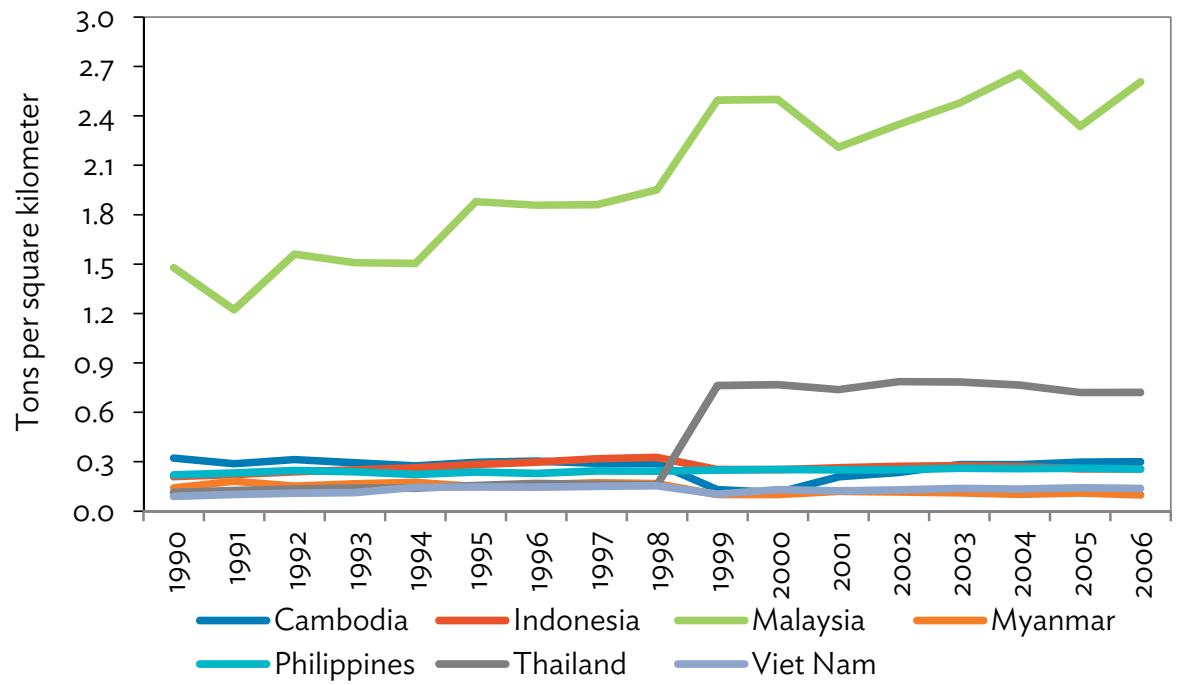

Note: Coastal shelf fishing pressure is defined as trawling and dredging catch (tons) per square kilometer of exclusive economic zone.

Source: Booth and Pauly 2011.

In terms of marine protection, only $0.22 \%$ of Myanmar's territorial water is protected based on 2010 and 2012 data. This proportion is exceptionally low, compared with the region's average of $2.26 \%$. More strikingly, Myanmar barely expanded the area of its protected exclusive economic zones in the past 2 decades, while most of its neighbors have expanded them substantially (Figure 9).

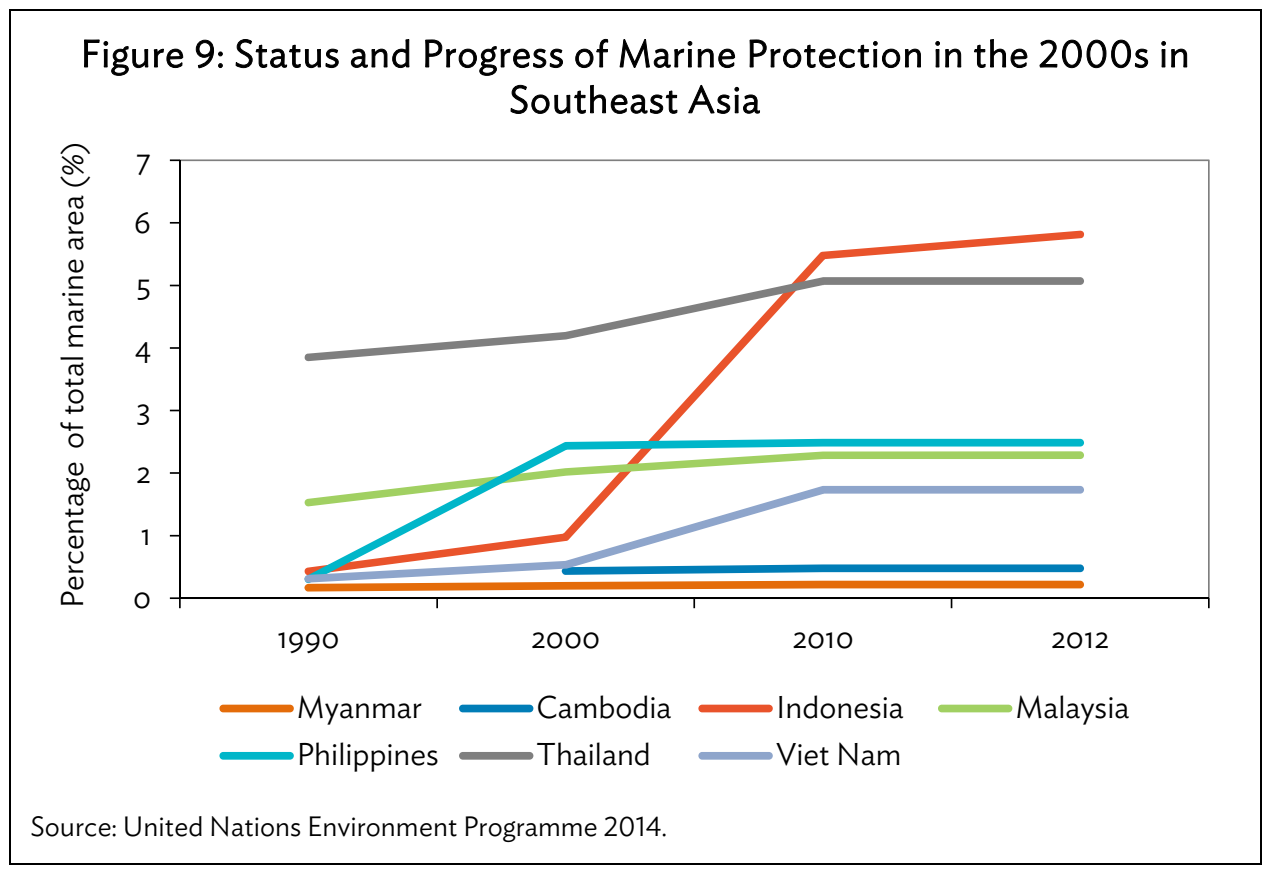


As long as fishing pressure remains low, the low level of marine protection may not be a major constraint to the sustainability of marine resources and fish stocks. However, as Myanmar opens its markets, more advanced fishing equipment becomes more readily available, and more market opportunities for fisheries products develop, fishing pressure may become much stronger. Against this backdrop, improved marine protection may become much more important in the future.

\section{E. Climate Change May Amplify Degradation and Loss of Natural Resources}

Forests are vulnerable to climate change, as forest tree species with long lifecycles have little ability for migration of species distribution or replacement with lines tolerant to new growing conditions. Hannah et al. (2013) projected $60 \%$ loss of suitable habitat in the Himalayan area of Myanmar due to changes in rainfall and temperature. The effects of more extreme climatic events and potentially greater forest fire risks may compound this, as dry seasons lengthen and traditional, prescribed burning systems break down. Coral bleaching may also be expected and fisheries stocks may migrate. As dry seasons lengthen, water resource constraints may become more severe.

The loss of regulatory functions of natural resources will also increase the impacts of climate change (Box 2). As forest cover declines, the effects of more intense rainfall will be exacerbated, as watershed runoff is increased and flooding risk rises. Loss of mangroves will raise the vulnerability to cyclones of coastal environments. Thus, natural resource protection is important to minimize risks from global warming, and climate change needs to be incorporated into natural resource management.

\section{Box 2: Myanmar's Vulnerability to Climate Change}

Myanmar's climate is already changing. Data from weather stations show that it has experienced changes in annual total rainfall and mean temperature (CRU-UEA 2014). Greater rainfall was observed by weather stations located in the northern and coastal regions of the country, while the opposite was observed in the mid and eastern regions. Higher temperatures were observed in the majority of the weather stations, except in the lower mid-central region. Observations also suggest that the average length of the monsoon season has shortened (MOAI 2010).

The frequency and magnitude of extreme climatic events such as drought, extreme temperatures, tropical cyclones, and flooding have grown (UNEP, MOECAF, and Ministry of Transport 2012). Severe drought periods were more frequent between 1990 and 2002. Cyclones have also become more frequent: before 2000, cyclone landfalls happened approximately once every 3 years; since then, cyclones have hit Myanmar every year, including Cyclone Nargis, which caused the most destruction to date. From 1900 to 2000 , only 12 major flooding events were recorded in the country, yet there have already been four major floods in the 2000s.

Climate change will be pronounced, exacerbating the effects observed so far. The Myanmar Department of Meteorology and Hydrology compared the Providing Regional Climates for Impacts Studies' downscaled modelling of temperature and rainfall with a recent reference period to 20202050 under the A2 Intergovernmental Panel on Climate Change Standard Reference Scenario. Mean temperatures increased 0.8 to 1.4 degrees, and rainfall increased by up to 660 millimeters, over this relatively short period. 
Box 2 continued

\begin{tabular}{|c|c|c|c|c|c|c|c|c|}
\hline \multirow[b]{4}{*}{ Station } & \multicolumn{8}{|c|}{ Box Table 2.1: Actual and Modelled Temperature and Rainfall for Different Periods } \\
\hline & \multicolumn{4}{|c|}{ Mean Temperatures } & \multicolumn{4}{|c|}{ Mean Rainfall (millimeters) } \\
\hline & \multicolumn{2}{|c|}{$1971-2000$} & \multicolumn{2}{|c|}{ A2 Projection } & \multicolumn{2}{|c|}{$1971-2000$} & \multicolumn{2}{|c|}{ A2 Projection } \\
\hline & Observed & $\begin{array}{c}\text { A2 } \\
\text { Output }\end{array}$ & $\begin{array}{l}2001- \\
2020 \\
\end{array}$ & $\begin{array}{c}2020- \\
2050\end{array}$ & Observed & $\begin{array}{c}\text { A2 } \\
\text { Output }\end{array}$ & $\begin{array}{l}2001- \\
2020 \\
\end{array}$ & $\begin{array}{r}2020 \\
2050 \\
\end{array}$ \\
\hline Myitkyina & 24.4 & 24.3 & 24.9 & 25.4 & 1668 & 2,203 & 2,431 & 2,400 \\
\hline Mandalay & 27.6 & 27.7 & 28.1 & 28.5 & 812 & 931 & 1,037 & 1,085 \\
\hline Sittway & 25.7 & 24.0 & 24.6 & 25.1 & 4593 & 4,117 & 4,073 & 4,778 \\
\hline Kengtung & 23.2 & 23.3 & 23.7 & 24.3 & 1250 & 1,314 & 1,340 & 1,350 \\
\hline $\begin{array}{c}\text { Mingladon } \\
\text { (Yangon) }\end{array}$ & 27.5 & 27.4 & 28.1 & 28.8 & 2661 & 2,661 & 2,604 & 2,805 \\
\hline Pathein & 27.1 & 27.2 & 27.8 & 28.4 & 2843 & 2,960 & 3,005 & 3,252 \\
\hline Dawei & 26.6 & 27.6 & 28.1 & 28.7 & 5376 & 3,547 & 3,489 & 3,701 \\
\hline
\end{tabular}

Note: Using the Providing Regional Climates for Impacts Studies regional downscaling model under the A2 Special Report on Emission Scenario (SRES).

Source: Ministry of Environmental Conservation and Forestry 2010.

According to Kreft and Eckstein (2013), Myanmar had the world's second highest climate risk between 1993-2012 based on losses, damage to property, and death tolls attributed to extreme weather events. And climate change is expected to increase the frequency of such events. Climate change-attributable future climatic hazards identified by MOECAF (2010) include: (i) cyclones, (ii) floods, (iii) intense rainfall, (iv) extreme day temperature, (v) drought, and (vi) sea level rise. The coastal region shows high risk to four out of six climate change-related climatic hazards. Combining climate risk information with population data (Table 3) illustrates that $20 \%$ of the population (coastal region) is at high risk to four climatic hazards, while $82 \%$ of the population is at high risk to at least one of the hazards.

Box Table 2.2: Population and Climatic Hazard Risk of Different State/Division of Myanmar

\begin{tabular}{|c|c|c|c|c|c|c|c|}
\hline \multirow[b]{2}{*}{ Division/State } & \multirow[b]{2}{*}{ Population } & \multicolumn{6}{|c|}{ Climatic Hazards } \\
\hline & & Cyclone & Flood & $\begin{array}{l}\text { Intense } \\
\text { Rainfall }\end{array}$ & $\begin{array}{l}\text { Extreme Day } \\
\text { Temperature }\end{array}$ & Drought & $\begin{array}{l}\text { Sea Level } \\
\text { Rise }\end{array}$ \\
\hline Ayeyarwady & $5,842,093$ & High & High & High & Low & Low & High \\
\hline Bago & $4,515,202$ & Low & High & Medium & Medium & Medium & Medium \\
\hline Chin & 502,683 & Medium & Low & Medium & Low & Low & None \\
\hline Kachin & $1,215,644$ & Medium & Medium & Medium & Low & Low & None \\
\hline Kayah & 234,560 & Low & Low & Medium & Low & Medium & None \\
\hline Kayin & $1,324,504$ & Medium & Medium & Medium & Low & Low & None \\
\hline Magway & $3,759,749$ & Medium & Medium & Low & High & High & None \\
\hline Mandalay & $5,759,958$ & Low & Medium & Low & High & High & None \\
\hline Mon & $1,874,205$ & High & Low & High & Low & Low & Medium \\
\hline Rakhine & $2,947,859$ & High & High & High & Low & Low & High \\
\hline Sagaing & $4,842,801$ & Medium & High & Medium & Medium & High & None \\
\hline Shan & $4,474,830$ & Low & Low & Low & Low & Low & None \\
\hline Tanintharyi & $1,208,212$ & Low & Low & High & Low & Low & Medium \\
\hline Yangon & $5,706,846$ & High & High & High & Low & Low & Medium \\
\hline
\end{tabular}

Source: Ministry of Environmental Conservation and Forestry 2010. 


\section{POLLUTION MANAGEMENT}

\section{A. Land/Waste}

Industrialization and urbanization have brought the challenge of wastewater and solid waste management. As of 2007, Myanmar's annual urban solid waste generation was estimated to reach about 690,000 tons, from Yangon city and 238 townships alone. By another estimate, in Yangon city, about 2,900 tons of solid waste are generated daily, yet only $54 \%$ of that amount is collected daily (Aye 2005).

Myanmar's municipal solid waste is composed mostly of organic materials (73\%) and paper/cardboard (18\%), while nonbiodegradable materials such as plastic account for only about $2 \%$. Currently, its disposal methods are through traditional open dumping (73\%), although $22 \%$ of waste is being recycled. The country does not have sanitary landfills. Waste collection capacity, as measured by the ratio of solid waste collected to total waste generated, has been increasing for many major cities. During $1990-2008$, it increased from $70 \%$ to $80 \%$ for Myitkyina, $80 \%$ to $90 \%$ for Monywa, and $40 \%$ to $70 \%$ for Mawlamyine, while it remained stable at $90 \%$ for Mandalay. However, this dropped from $85 \%$ to $72 \%$ in Yangon City (ASEAN 2009).

Cities such as Yangon and Mandalay are now prioritizing solid waste management, as indicated by the increased budget allocation for it (NCEA and UNEP 2008). Despite these improvements, solid waste management in the country remains inadequate for full collection rates, and coverage of rural areas is sparse. Logistical support is needed (vehicles and additional workers) and comprehensive solid waste management planning is not yet developed. As the country moves toward industrialization, with the growth of its urban population, waste composition will change and volumes grow. A more efficient solid waste management system will be needed to cope with increased waste pressure.

\section{B. Water}

Myanmar's marine and river waters absorb most of the country's land-based wastes. But thus far, they remain largely free of pollution. Water quality screening conducted by the University of Yangon in 2010 showed that major physiochemical water properties in the major coastal zones of the Rakhine, Deltaic, Dawei, and Myeik regions remain within acceptable quality standards (BOBLME 2011). No significant pollution incident has ever been recorded in major coastal ports to date. However, signs of higher pollutant concentrations are starting to be noted along the mouth of Yangon River. Inland water bodies are starting to show chemical and nutrient loading, with high nitrate concentrations observed in Inle Lake and the Ayeyarwady River system (Akaishi et al. 2006).

As the country faces industrialization and economic development, land-based pollutants from municipal, agricultural, and industrial activities will increase. For example the total mass of pesticides applied by farmers increased 331\% between 2009 and 2010, and many of these will ultimately end up in water resources (CSO 2012).

Mining, as an essential economic sector, is a major and growing source of water pollution. Since the opening up of the country to foreign investors, the Ministry of Mines granted hundreds of official and unofficial mining concessions to both local and foreign investors. Mining has expanded rapidly, with the number of mines increasing 293\% between 2009 and 2010. Mines are associated with water pollution problems from tailings (CSO 2012). In the absence of detailed regulations on hazardous 
materials, pollutant discharges and wastewater treatment, water pollution is likely to become an issue in the near future.

\section{Air}

Air pollution is becoming a problem in urban areas. While sulfur dioxide and nitrogen dioxide air concentrations remain below World Health Organization standards, particulate matter (PM) concentrations in urban areas are already at alarming levels. Based on WHO (2011), the cities of Yangon and Mandalay are noted to have one of the highest PM10 (particulate matter which passes through a size-selective inlet with a 50\% efficiency cut-off at 10 micrometer [ $\mu \mathrm{m}]$ aerodynamic diameter) concentration among other cities in Southeast Asia (Figure 10). Coarse PM10 levels in Yangon and Mandalay were measured from 71.75 micrograms per cubic meter $(\mu \mathrm{g} / \mathrm{m} 3)$ to 112.49 $\mu \mathrm{g} / \mathrm{m} 3$ along commercial areas, $61.7 \mu \mathrm{g} / \mathrm{m} 3$ to $65.3 \mu \mathrm{g} / \mathrm{m} 3$ in residential areas, and $131.54 \mu \mathrm{g} / \mathrm{m} 3$ to $136.92 \mu \mathrm{g} / \mathrm{m} 3$ in industrial areas (Table 9) (the upper limit for acute and infrequent events in the United States National Ambient Air Quality Standards is $135 \mu \mathrm{g} / \mathrm{m3}$; MOECAF 2013, ASEAN 2014). A primary cause of this pollution is reconditioned vehicle emissions. Given the rapid rise in the number of motorized vehicles on the road, (total vehicles more than tripled between 2007 and 2012), these problems are likely to become much worse if not regulated. Also, according to MOECAF (2010), the prevalent use of biomass, particularly fuelwood and charcoal for household cooking and heating, contributes to the high levels of particulate matter in the air.

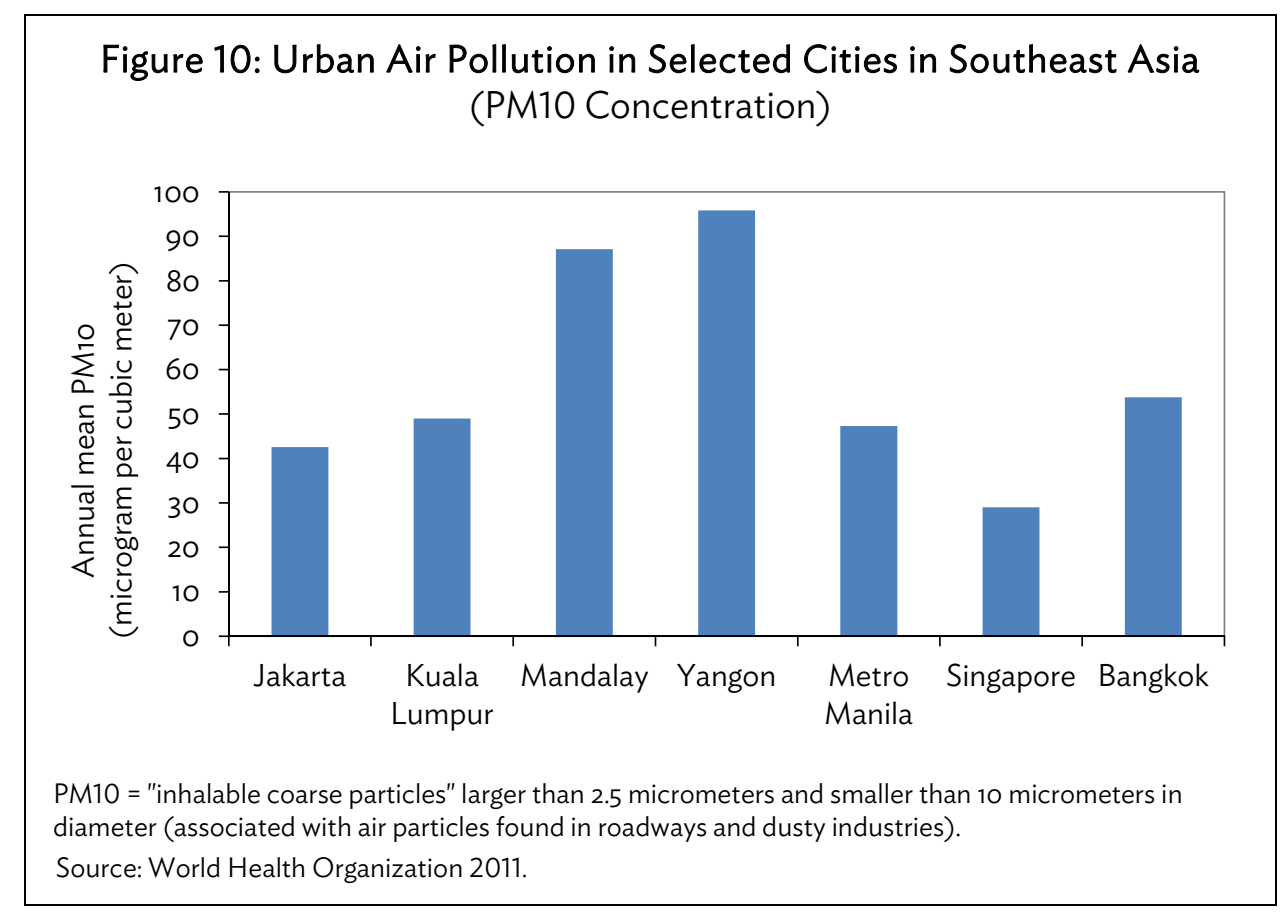

In contrast, Myanmar has the lowest sulfur dioxide $\left(\mathrm{SO}_{2}\right)$ emissions per capita in Southeast Asia (Figure 11), largely as an artefact of limited industrialization to date. This is likely to change as industrial production increases with economic development. 
Table 9: Daily Average Air Quality in Yangon (2007) and Mandalay (2008)

\begin{tabular}{|c|c|c|c|c|c|c|c|c|}
\hline \multirow[b]{2}{*}{ Site } & \multicolumn{4}{|c|}{$\begin{array}{c}\text { Yangon (2007) } \\
(\mu \mathrm{g} / \mathrm{m} 3)\end{array}$} & \multicolumn{4}{|c|}{$\begin{array}{c}\text { Mandalay (2008) } \\
(\mu \mathrm{g} / \mathrm{m} 3)\end{array}$} \\
\hline & TSP & PM10 & $\mathrm{SO}_{2}$ & $\mathrm{NO}_{2}$ & TSP & PM10 & $\mathrm{SO}_{2}$ & $\mathrm{NO}_{2}$ \\
\hline Residential & 168.61 & 68.59 & 1.14 & 23.22 & 213.08 & 61.67 & 0.98 & 17.80 \\
\hline Commercial & 342.58 & 177.69 & & & 495.87 & 112.49 & 0.86 & 32.13 \\
\hline Industrial & 127.32 & 66.95 & 0.37 & 28.36 & 350.57 & 131.54 & 1.50 & 19.14 \\
\hline
\end{tabular}

$\mu \mathrm{g} / \mathrm{m3}=$ microgram per cubic meter, $\mathrm{NO}_{2}=$ nitrogen dioxide, $\mathrm{PM} 10=$ "inhalable coarse particles" larger than 2.5 micrometers and smaller than 10 micrometers in diameter (associated with air particles found in roadways and dusty industries), $\mathrm{SO}_{2}=$ sulfur dioxide, TSP = total suspended particles.

Sources: Ministry of Environmental Conservation and Forestry 2013; National Commission for Environment al Affairs and United Nations Environment Programme Regional Resource Center for Asia and the Pacific 2008; Association of Southeast Asian Nations Secretariat 2014, based on a 3-day sampling period.

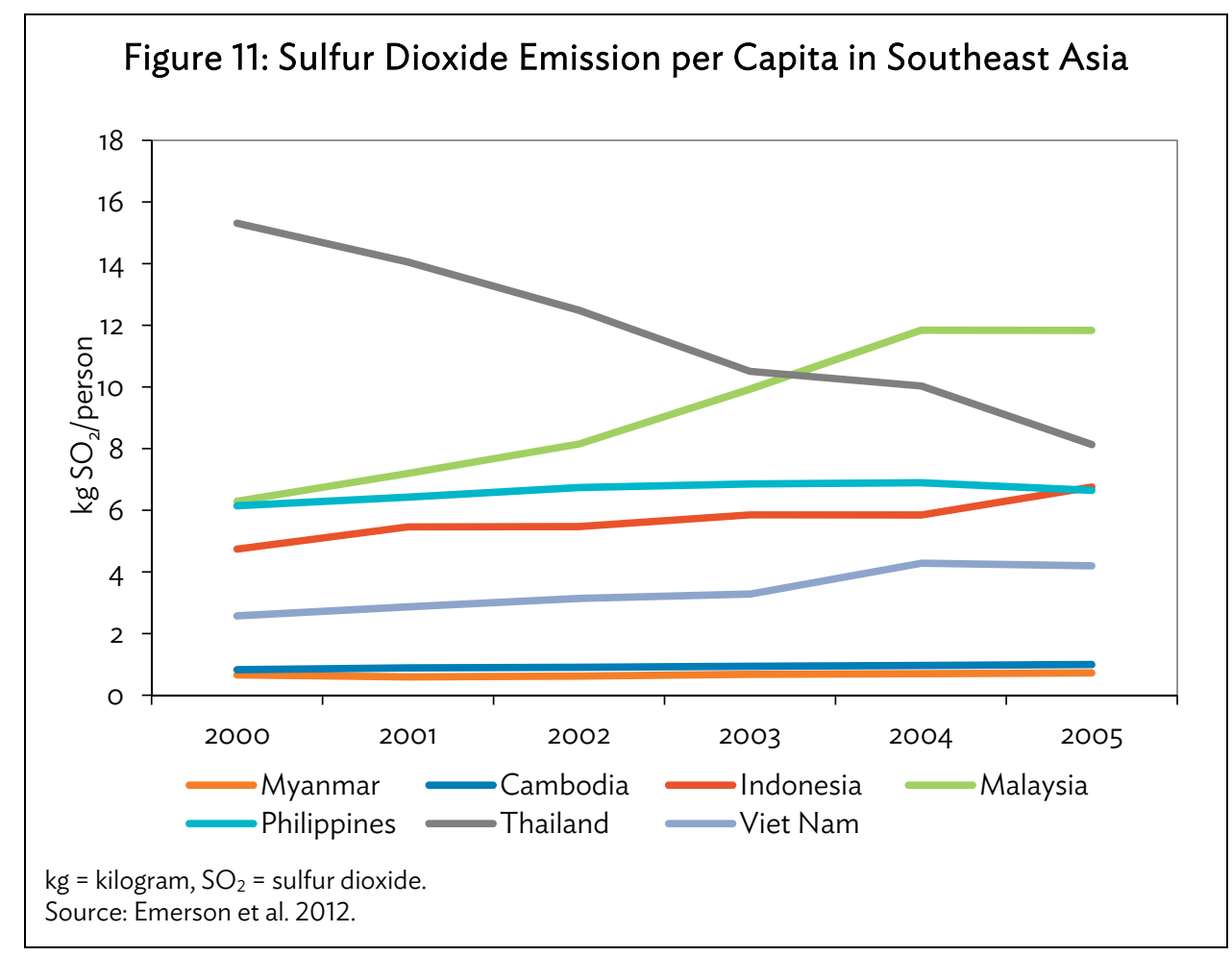

More generally, Myanmar has no air quality monitoring system, air quality standard, or monitoring stations for air quality (Bathan-Baterina, Patdu, and Ajero 2013). But the government has "formulated the development of natural gas reserves" and encourages the use of Compressed Natural Gas for city transportation. Yet, as long as most natural gas is exported, this will not substitute for much diesel and petrol and associated emissions. Clearly, much regulatory development is needed to cope with the air quality pressures that will accompany economic diversification and growth.

\section{Greenhouse Gas Emissions}

Myanmar currently has negative net greenhouse gas emissions, largely due to its forestry sector removals in remaining forest stands (Table 10). However, this carbon removal is falling as forest areas shrink and are degraded. The vast majority of emissions are from agriculture and from deforestation (Table 11). However, per capita emission levels in the absence of forest sinks are still low in comparison 
to the rest of the world. This will rise strongly as the economy develops and consumption of goods and energy increases.

Table 10: Greenhouse Gas Emissions for Myanmar

\begin{tabular}{lrrr}
\hline & \multicolumn{3}{c}{ Emissions, in $\mathrm{Gg} \mathrm{CO}_{2}$ equivalent } \\
\cline { 2 - 4 } & 2000 & 2003 & \multicolumn{1}{c}{2005} \\
\hline $\mathrm{CO}_{2}$ emissions without LUCF & $7,907.2$ & $8,406.6$ & $8,264.6$ \\
$\mathrm{CO}_{2}$ net emissions/removals by LUCF & $-108,564.7$ & $-98,290.1$ & $-95,774.7$ \\
$\mathrm{CO}_{2}$ net emissions/removals with LUCF & $-100,657.4$ & $-89,883.5$ & $-87,510.1$ \\
GHG emissions without LUCF & $33,995.7$ & $36,134.4$ & $38,374.9$ \\
GHG net emissions/removals by LUCF & $-104,202.2$ & $-98,290.1$ & $-95,774.7$ \\
GHG net emissions/removals with LUCF & $-70,206.5$ & $-62,155.7$ & $-57,399.8$ \\
\hline
\end{tabular}

$\mathrm{CO}_{2}=$ carbon dioxide, $\mathrm{Gg}$ = gigagram, $\mathrm{GHG}=$ greenhouse gas emission, $\mathrm{LUCF}=$ land-use change and forestry.

Source: United Nations Framework Convention on Climate Change 2013.

Table 11: Initial Result of Myanmar's National Greenhouse Gas Inventory, 2010

\begin{tabular}{lccc}
\hline Source/Sink & $\mathrm{CO}_{2}$ Removal (Gg) & $\begin{array}{c}\mathrm{CO}_{2 \mathrm{e}} \text { Total } \\
\text { Emissions (Gg) }\end{array}$ & $\begin{array}{c}\mathrm{CO}_{2 \mathrm{e}} \mathrm{Net} \\
\text { Emissions }(\mathrm{Gg})\end{array}$ \\
\hline Energy sector & 0 & 7,860 & 7,860 \\
Industrial sector & 0 & 460 & 460 \\
$\begin{array}{l}\text { Agriculture sector } \\
\text { including livestock }\end{array}$ & 0 & 22,840 & 22,840 \\
Land-use change and & & & \\
$\quad$ forestry sector & 142,220 & 40,400 & $-101,820$ \\
Waste sector & 0 & 2,830 & 2,830 \\
Total & 142,220 & 74,400 & $-67,820$ \\
\hline
\end{tabular}

$\mathrm{CO}_{2}=$ carbon dioxide, $\mathrm{CO}_{2 \mathrm{e}}=$ carbon dioxide equivalent, $\mathrm{Gg}=$ gigagram .

Sources: Ministry of Environmental Conservation and Forestry 2010; Institute for Global Environmental Strategies 2012.

Myanmar's forests currently offer valuable carbon sequestration to the rest of the world as a global public good. However, this good is at peril, as its value is not directly captured by the economic agents that drive land-use change.

\section{POLICY MEASURES TO CONTAIN ENVIRONMENTAL DEGRADATION}

\section{A. Policy Framework}

There is recognition of the importance of the environment in Myanmar, which has been a party to various multilateral environmental treaties and agreements. The country's National Environmental Policy of 1994 has constituted environmental rules on the utilization, conservation, and prevention of degradation of its water, land, forest, mineral, marine resources, and other natural resources.

Following the development of this national policy, the country drafted its Agenda 21 commitment (1997) to implement integrated management of natural resources and provide a blueprint to reach targets of environmentally sustainable development. ${ }^{3}$ In the 2008 Constitution, an environmental provision stated that the government shall protect and conserve the natural

3 This followed the United Nations Framework that is in line with the Millennium Development Goals of achieving sustainable management of natural resources, integrated economic development, and sustainable social development. 
environment. But it also stated that the "national legislature can, but does not need to enact laws to protect the environment and help restore areas degraded or damaged by mining and forestry activities or those that have experienced destruction of plants, wildlife, and habitat (BEWG 2011)." Laws have given the state and regional legislatures' power to regulate environmental protection, but this is only within the boundaries of (undeveloped) legislation passed by the National Legislature. Language in many provisions in the constitution is unclear and leaves gaps for interpretation, particularly regarding the ability of civil society to participate in natural resource management and customary land ownership.

The country's National Sustainable Development Strategy was launched in 2009 and reaffirmed its commitment to create a framework that integrates environmental considerations into future national development plans. The Strategy spelled out the country's goal for sustainable management of natural resources by prioritizing improved forest resource management, sustainable energy production and consumption, biodiversity conservation, sustainable freshwater resources management, sustainable management of land resources and mineral resource utilization. The country's main environmental policies have embraced wording regarding harmony and balance between the protection of its environment and the goal of achieving economic growth. Based on these policy principles, various laws were promulgated to govern the environment sector (Table 12). In addition, Myanmar became a party to various multilateral environmental treaties and agreements (Table 13).

\section{Table 12: Major Environment-Related Policies and Laws in Myanmar}

\begin{tabular}{|c|c|c|}
\hline Law and Regulation & Year & Purpose \\
\hline $\begin{array}{l}\text { Territorial Sea and Maritime } \\
\text { Zone Law }\end{array}$ & 1977 & $\begin{array}{l}\text { To define maritime zone, contiguous zone, exclusive economic zone, and } \\
\text { continental shelf; exclusive jurisdiction in respect of preservation and } \\
\text { protection of the marine environment, and prevention of marine pollution. }\end{array}$ \\
\hline $\begin{array}{l}\text { Fishing Rights of Foreign Vessels } \\
\text { Law }\end{array}$ & 1989 & $\begin{array}{l}\text { To conserve fisheries and to enable systematic operation in fisheries with } \\
\text { participation of foreign investors. }\end{array}$ \\
\hline Marine Fisheries Law & 1990 & $\begin{array}{l}\text { To conserve marine fisheries and to enable systematic operation in marine } \\
\text { fisheries. }\end{array}$ \\
\hline Forestry Law & 1992 & $\begin{array}{l}\text { To implement forest policy and environmental conservation policy, } \\
\text { prevent destruction of forest and biodiversity, conservation of natural } \\
\text { forests and establishment of forest plantations. }\end{array}$ \\
\hline National Environmental Policy & 1994 & $\begin{array}{l}\text { Sound environment policies in the utilization of water, land, forest, mineral } \\
\text { resources, and other natural resources; conserve and prevent degradation. }\end{array}$ \\
\hline $\begin{array}{l}\text { Protection of Wildlife and Wild } \\
\text { Plants and Conservation of } \\
\text { Natural Areas Law }\end{array}$ & 1994 & $\begin{array}{l}\text { To protect wildlife, wild plants and conserve natural areas, to contribute } \\
\text { toward works of natural scientific research, and to establish zoological } \\
\text { gardens and botanical gardens. }\end{array}$ \\
\hline Myanmar Mines Law & 1996 & To implement mineral resources policy. \\
\hline Fertilizer Law & 2002 & $\begin{array}{l}\text { To boost development of the agriculture sector, control fertilizer } \\
\text { businesses, and to facilitate conservation of soil and the environment. }\end{array}$ \\
\hline $\begin{array}{l}\text { Environmental Conservation } \\
\text { Law }\end{array}$ & 2012 & $\begin{array}{l}\text { To enable implementation of the Myanmar National Environmental } \\
\text { Policy. }\end{array}$ \\
\hline
\end{tabular}

Sources: Burma Environment Working Group 2011; Online Burma/Myanmar Library. http://www.ibiblio.org/obl/show.php?cat=1189\&lo=\&sl= 
Table 13: Myanmar's Membership in International and Regional Treaties

\begin{tabular}{|c|c|}
\hline Conventions & Year \\
\hline Vienna Convention for the Protection of the Ozone Layer & $1993(\mathrm{Ac})$ \\
\hline Montreal Protocol on Substances that Depletes Ozone Layer & $1993(\mathrm{Ac})$ \\
\hline International Convention for the Prevention of Pollution from Ships (MARPOL) & $1988(\mathrm{Ac})$ \\
\hline Agreement on the Networks of Aquaculture Centers in Asia and the Pacific Region & 1990 \\
\hline United Nations Framework Convention on Climate Change (UNFCCC) & $2003(A c)$ \\
\hline Treaty on the Non-Proliferation of Nuclear Weapons & $1992(\mathrm{Ac})$ \\
\hline Convention on International Civil Aviation Environmental Protection & $\ldots$ \\
\hline UN Convention to Combat Desertification & $1997(\mathrm{Ac})$ \\
\hline Convention on Biological Diversity & $1994(R)$ \\
\hline UN Convention on the Law of the Sea & $1996(R)$ \\
\hline International Timber Agreement & $1996(\mathrm{Ac})$ \\
\hline Convention on International Trade of Endangered Species of Wild Fauna and Flora & $1997(\mathrm{Ac})$ \\
\hline ASEAN Agreement on the Conservation of Nature and Natural Resources & 1997 (Ac) \\
\hline Cartagena Protocol for Bio-safety & $2008(R)$ \\
\hline ASEAN Agreement on Trans boundary Haze Pollution & $2003(R)$ \\
\hline Kyoto Protocol to UNFCCC & $2005(R)$ \\
\hline Stockholm Convention on Persistent Organic Pollutants & $2004(A c)$ \\
\hline Ramsar Convention on Wetlands & $2005(R)$ \\
\hline $\begin{array}{l}\text { Copenhagen Amendment on to the Montreal Protocol on Substances that Depletes the } \\
\text { Ozone Layer }\end{array}$ & $2009(A c)$ \\
\hline
\end{tabular}

... = not available, $\mathrm{Ac}=$ accession, $\mathrm{ASEAN}=$ Association of Southeast Asian Nations, $\mathrm{R}=$ ratification, UN = United Nations.

Sources: Burma Environment Working Group 2011; Online Burma/Myanmar Library. http://www.ibiblio.org/obl/show.php?cat $=1189 \&|0=\& s|=$

In 1990, the National Commission for Environmental Affairs (NCEA) was established and chaired by the Minister of Foreign Affairs to set up the country's environmental regulation and standards, create environmental policies on the use of natural resources and issue rules and regulations to control pollution. In 1994, the country's first National Environmental Law was drafted. This Law stipulated an environmental impact assessment requirement for which regulations, procedures, and implementation were never developed. In the same year, the NCEA also drafted two laws: the Environmental Protection Law and the Environmental Impact Assessment Rules, but both have remained unapproved since. Between 1997 and 2000, a set of environmental protection provisions has been drafted and redrafted by the government, with technical inputs and support from United Nations Environment Programme, but none has been approved as law. In 2012, the MOECAF combined the earlier Ministry of Forests with the NCEA to elevate the status of environmental regulation.

However, actual implementation of improved environmental regulations has lagged behind the general policy proclamations. While many stated commitments to environmental conservation have been made, few actual environmental protection measures have been made to date by the government, as key regulations and procedures are not yet approved. Nor have necessary policy conditions been put in place to control underlying drivers of environmental degradation. This is a particular area of weakness, as economic growth is progressing rapidly in Myanmar's neighbors and trading partners, particularly the PRC and India, increasing demands for resource-intensive imports. 


\section{B. Regulatory Processes}

Although the environment is receiving more government recognition as a priority consideration, Myanmar still has no ministry exclusively devoted to environmental regulation. Environmental conservation is most directly handled by the MOECAF, within which only one department (out of six) handles environmental issues. Those environmental issues principally pertain to environmental impact assessment, which is handled by a skeletal staff, in consultation with other relevant ministries.

A small division within the Department of Environmental Conservation is tasked with the development of regulations on discharges, pollution, waste disposal, and environmental quality, more broadly. Although there is effort toward developing environmental quality standards, these are not yet approved, and associated regulations on emissions and effluents are at initial phases. Broader coordination of environmental policy making with line ministries that regulate sources of pollution falls to the Environmental Conservation Committee, which spans a number of relevant union ministries. However, with the government including 36 ministries, such coordination is a challenge. Given the great amount of work to be done to develop an effective regulatory system, more effective arrangements are warranted.

Myanmar would benefit greatly from having a line ministry with clear accountability for environmental policy making across sectors, as is the case in most other countries. Development of such a ministry would be an important step toward establishing a critical mass for environmental planning and regulatory capacity, and would be a key resource for oversight of other line agencies.

Decision-making authority in Myanmar is rapidly evolving. Under the current administration, decentralization of decision making is a priority for governance reform. In 2010, state/region level parliaments were established, and their remit was expanded in 2013. As of late 2013, there are discussions about augmenting the topics that they cover. While forestry and natural resources issues are still limited to fuelwood, it is possible that the role of state/regional ministries may expand as decentralization is pursued. Although this decentralization may improve the representation of local community interests in decision making, changes in approval processes may also create uncertainties, power struggles, and opportunities for corruption, to the detriment of effective environmental governance.

At the same time, the presence of armed insurgency groups in border areas creates de facto decentralization, as these groups may in effect regulate natural resources in the domains that they control. This is compounded by government interests to secure holdings of contested areas through demarcation and issuance of large-scale concessions. Pressure to quickly establish control may lead to rapid approval of land-use projects by local groups. Moreover, rents may be obtained in the period when control by one party is clear and accountability to standard procedures is limited, creating incentives for quick forest clearance before accountability and wider transparency improves.

Even when control is not contested and the level of decision making is not in flux, regulatory procedures are constantly evolving in Myanmar. For example, assessment procedures by the Myanmar Investment Committee for new projects are still being defined, regulations on timber clearance and exports are changing, and environmental standards are under discussion. While, in the long run, this should lead to better regulation of environmental pressures, in the short-term, these changes may create uncertainty and pressure for damage before stricter regulations are implemented. 


\section{Protected Areas}

One of the few areas where there is a longer history of active protection is regarding specific natural conservation areas. For the past decade, Myanmar increased its protection coverage of biomes from $2.9 \%$ in 1990 to $3.6 \%$ in 2000 to $7.2 \%$ by 2012 (Figure 12). This is driven by the establishment of protection areas that have expanded steadily between 1996 and 2004 to cover $7.3 \%$ of total land area (ADB 2013). As a result, Myanmar has made the most progress in state extent of biome protection among developing countries in Southeast Asia. However, the 2010 rate is still below the world average of $9.45 \%$ and the target of $17 \%$ set by the Convention of Biological Diversity.

Figure 12: Terrestrial Protection Areas in Southeast Asia, 1990-2012

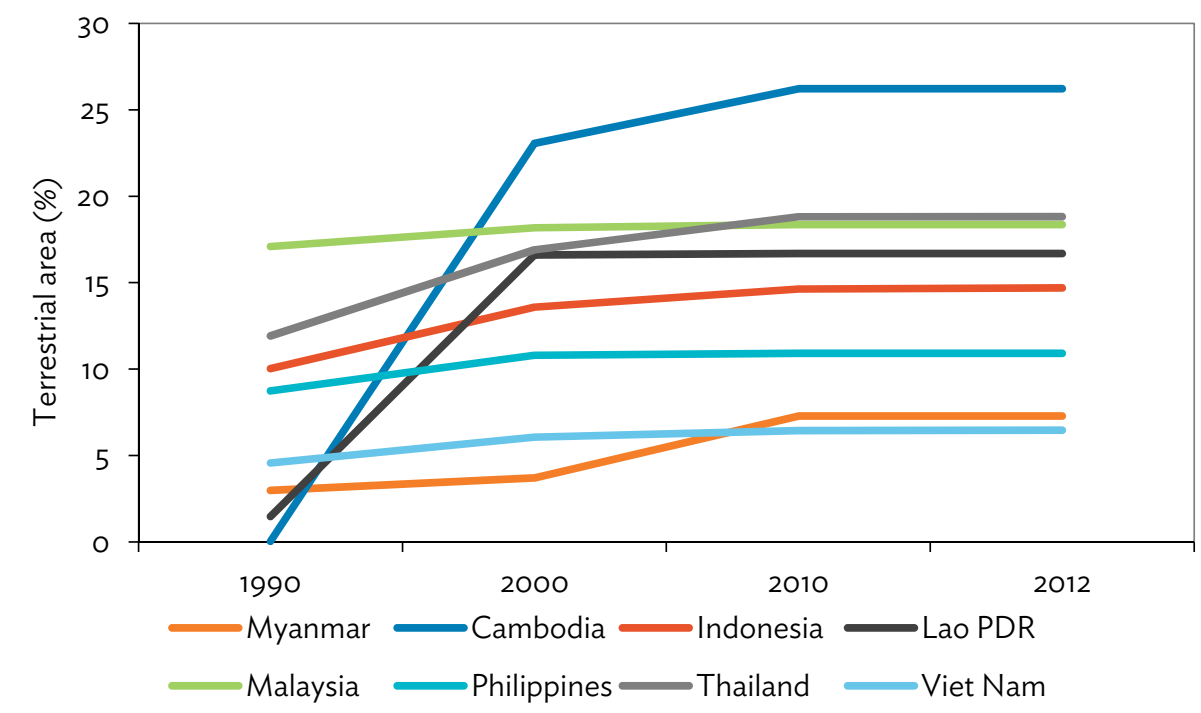

Lao PDR = Lao People's Democratic Republic.

Source: World Database on Protected Areas. http://www.wdpa.org/Statistics.aspx (accessed on 3 February 2014).

At the same time, these protected areas appear not to be covering critical biodiversity and habit for critical species, as many areas have been designated in conflict or border areas, presumably so that designation can come at minimal costs to competing economic uses of land. For example, MOECAF and the Wildlife Conservation Society held a participatory process in 2013 to identify Key Biodiversity Areas (Wildlife Conservation Society 2013). Of the 132 areas identified, only 35 had notified protected status. Similarly, none of the three sites identified by the Alliance for Zero Extinction as the last remaining habitat of endangered species is protected (Alliance for Zero Extinction 2010).

Protected areas, furthermore, are subject to ineffective protection. Rao, Rabinowitz, and Khaing (2002), in a review of protected areas, found widespread violation of protection rules, including hunting, and encroachment in protected areas. Staff management capacity was observed as limited with only $35 \%$ of protected areas have $50 \%$ or more trained staff, and a majority of protected areas lacked an implemented planning document. For protected areas to effectively serve conservation purposes, protected designations need to be better prioritized, expanded, and supported with more skilled staff. 


\section{Safeguards}

Myanmar is opening to foreign investment, which creates a need to ensure that this investment does minimal harm to the natural environment in the absence of appropriate environmental regulations. Although Myanmar has allowed foreign direct investment (FDI) since its 1988 Investment Law, sanctions imposed on it during the 1990 s by the United States government and other Organisation for Economic Co-operation and Development countries effectively impeded much investment from countries other than in Asia. This was further compounded by a dual exchange rate system in which official exchange rates to foreign currency were many times lower than free market values. However, as a result of political reforms in 2011, 2012, and 2013, sanctions have largely been lifted, enabling foreign investment into the country, and the kyat has been freely floating since 2012.

In late 2012, Myanmar approved a new Investment Law, which opened the country further to FDI by lower requirements for domestic ownership and expanded the number of industries in which foreign ownership is permitted. In addition, the new law enables foreign long-term leasing of land and involvement in plantations and agriculture. Investors are expected to be highly attracted by the country's natural resources, as well as its strategic position in the midst of Chinese, Indian, and Southeast Asian markets, which are all rapidly growing.

With FDI increasingly available and less restricted, a flurry of new projects is anticipated. An important share of these projects is likely to be based on extractive industries that exploit the rich array of natural resources possessed by the country or that are in industries with higher levels of emissions. At the same time, environmental regulations on natural habitat conservation, discharge/pollution, waste treatment, and remediation are underdeveloped and lack enforcement capacity. This leaves safeguard processes as the only effective tool available for mitigating projects with potential for large environmental destruction, in the face of many likely new pressures.

While Myanmar technically began to require environmental impact assessment in 1994, the development of environmental impact assessment procedures and regulations was initiated only recently. Myanmar is in the process of developing modalities for environmental impact assessment implementation, and faces conflicting interests and mandates in so doing. For example, the Myanmar Investment Commission currently stipulates that all environmental assessment should be completed within 90 days of proposal receipt. This is not sufficient time for a detailed environmental impact assessment to be conducted. It is envisaged, but not yet certain, that such requirements will be made more appropriate as formal impact assessment procedures are finalized.

More broadly, it is critical that all potentially deleterious investments are subjected to environmental impact assessment procedures. Many developments pass through different ministries, levels of government, and channels, and there is no mechanism to prevent them from bypassing environmental safeguard requirements if the project is not submitted to MOECAF for screening. Effective data clearinghouses and standardized mechanisms for interministerial communications are needed to ensure that all potentially damaging investments, such as large-scale agribusiness concessions are fully vetted.

Environmental impact assessment itself is unlikely to be meaningful without meaningful transparency and civil society attention to the assessment process and mitigation measures for potential damage. This civil society attention is currently often lacking in Myanmar, as a result of its history of state controls on the expression of critical ideas and protest, as well as the low level of 
education of many inhabitants. Improvement of awareness and creation of a space for free criticism and discourse is essential to safeguard effectiveness.

As the econometric analysis of deforestation determinants illustrates, concession allocation is currently associated with major loss of closed forest areas. Given the special importance of this pressure, it is essential that safeguard policies mitigate these effects in the future by effectively identifying and halting the distribution of such areas to concessions intended to involve forest clearance.

\section{E. Tenure}

In Myanmar, all land belongs to the state, although tradable use rights are issued to individuals for farming and other activities. However, there is little to no written documentation of these use rights (Haggblade et al. 2013). As a result, tenure is uncertain, as there is no way for the use rights to be validated, and land can be "grabbed" by powerful interests with connection to state agencies, displacing farmers who are pushed to the forest boundary. This is compounded by the lack of an updated landuse map, such that forest encroachment is difficult to identify and halt.

State land ownership also allows for rent-seeking by agencies involved in deforestation. Since state lands may be allocated at less than market values, when royalties for forest cleared for plantation development are collected at less than the full market value of the cleared timber, forest clearance is essentially subsidized.

Clarifying tenure, such that displacement is minimized, encroachment is identifiable and the presence of active land markets assures that the full economic value of land and resources is encompassed in land sales prices will help to minimize subsidies for clearance. As a result, these simple measures can help to reduce deforestation.

Many resources in Myanmar are currently under open access, as they belong to the state and lack rules to regulate exploitation. This is particularly the case for forestry and fisheries, where fuelwood and fish collection are not effectively regulated. As a result, these common resources, particularly for fuelwood, can be overexploited, as each individual actor benefits more from the decision to exploit than to conserve resources in the absence of expectations of conservation decisions by others. To help address this situation, Myanmar has set targets for community forestry, but progress remains limited in terms of actual areas designated for community management and numbers of community groups organized. Establishing effective stewardship over a common pool of resources is necessary to mitigate incentives for overexploitation. However, it is not simple, and requires investment in tenure, planning, and management capacity, as well as institutions.

\section{F. Market Incentives}

\section{Implicit Subsidies to Forest Clearance}

Current concession allocation in Myanmar effectively subsidizes the clearance of "conversion timber," as such timber is often illegally exported over land borders from concessions that are near to neighboring countries, and this involves little remuneration to the state of the market value of the timber cleared. This is implicitly recognized in a patronage system in which timber-rich concessions are reportedly allocated as rewards for services to the government, and is evidenced in a low proportion of concession areas planted, which suggests that the main economic returns from concessions may not 
lie in the production practices for which they were ostensibly allocated (Woods 2013a). Regression results from this paper further suggest that agribusiness concessions are a primary driver of deforestation in Myanmar.

This means that it is essential that concession allocation be reformed if deforestation is to be reduced. Two measures are essential to this reform. First, high conservation value natural forests should be demarcated and excluded from concession schemes in an open and transparent manner, according to rules that can be easily monitored. Second, royalties collected on conversion timber should be raised, such that they reflect the full economic value of the wood cleared, and clearance is not subsidized. To underpin both measures, forest inventories should be conducted for all prospective concession areas prior to allocation, and should be publicly shared as part of safeguard procedures.

\section{Demand for Extractive Resources}

One important potential driver of environmental degradation in Myanmar is the overexploitation of natural resources, particularly fuelwood, as $73 \%$ of the population relies on fuelwood as the primary source of energy (ADB 2013). The development of substitute sources of clean energy thus offers substantial potential reduce pressure on natural forest resources, and attendant biodiversity and climate services.

An important share of Myanmar's timber is exported, and its neighbor, the PRC and India have growing demand for timber imports. This may create strong pressure for forest clearance. To mitigate this, Myanmar initiated an export ban on unprocessed logs in April 2014, which is intended to reduce pressure on forests by depressing domestic log prices while stimulating domestic processing industries. As long as there is processing undercapacity, effective implementation of such a policy will help to alleviate forest pressure, as the returns to forest clearance are depressed (Box 3). However, if the export ban on unprocessed wood leads to a large differential between domestic and world wood prices, it creates an opportunity for export-oriented processors to generate rent. This opportunity for rent may lead to processing overcapacity in the mid- to longer-term, with attendant increased domestic demand for timber. As a result, it is important to implement the policy in the context of adequate safeguard measures to ensure that processing overcapacity is not created.

At the same time, such a policy is contingent upon enforcement capacity. Currently, a large share of exported timber is exported illegally. To effectively regulate the forms of timber exported, the effectiveness of border controls on shipments will need to be increased.

\section{Markets for Environmental Goods and Services}

Remaining natural forests and mangroves in Myanmar offer important environmental services as public goods for the rest of the world, such as reserves for threatened biodiversity, as well as providing important sources of carbon storage and sequestration. However, as public goods, there is no market that allows these goods to be priced, and there is no market incentive to those who can extract timber and fuel from forest clearance for preservation. Developing effective mechanisms that allow for compensation for the preservation of environmental services could help to ensure that these public goods are maintained at economically optimal levels. However, doing so is first contingent upon having clear tenure and accountability for forest management. 


\section{Box 3: Increasing the Sustainability and Economic Contribution of Forest Resources}

Myanmar's forest sector is dominated by unprocessed log exports, with the value of exported roundwood being more than 10 times than that of exported sawn timber, on a rising trend (box figure). This limited processing has achieved little value addition for forest products.

To address this, unprocessed roundwood was banned for export in April 2014-a positive step in line with the policies of most other forest-rich countries. If enforced, the ban should depress domestic roundwood prices, and reduce economic incentives for deforestation.

However, enforcement is uncertain given the large volume of timber that is already exported illegally over Myanmar's long, porous, and contested land borders. Moreover, the ban requires only a low level of domestic processing, with sawn timber exports still permitted, and there is no accompanying strategy to develop a domestic processing industry, which currently only has capacity for a tiny fraction of the sustainable production potential.

Composition of the Value of Primary Wood Exports

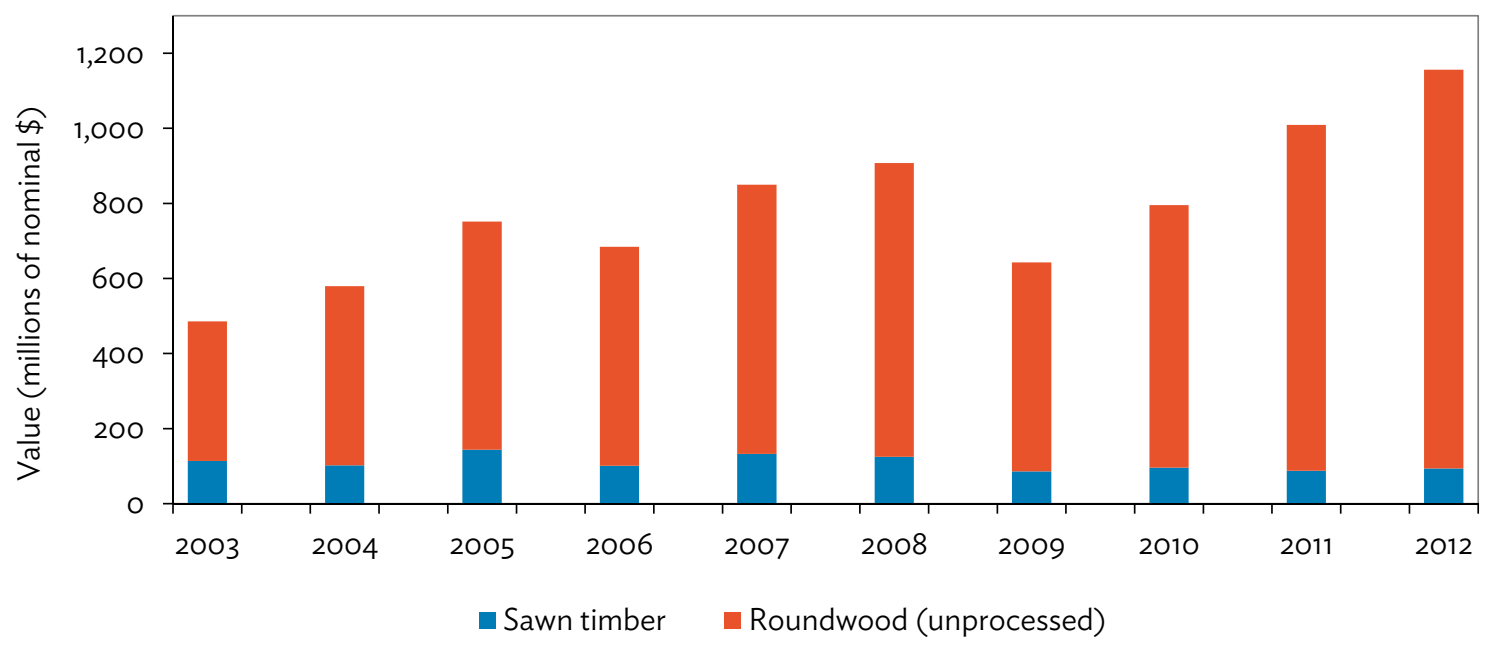

Note: Data based on import statistics reported by countries importing wood from Myanmar.

Source: UN Comtrade Database. http://comtrade.un.org/ (accessed April 2014).

To maximize the sustainable contribution of forest resources to economic development, Myanmar should develop a strategy that integrates private sector processing industry development with scientific forest management, such that capacity for value addition is closely matched to sustainable yield levels and wood quality. In so doing, Myanmar will need to both address current processing undercapacity while avoiding the potential pitfall of developing excess processing capacity over the longer-term, which can also lead to pressure for overextraction and suboptimal timber yields. In parallel, new institutional arrangements and incentives need to be established for extraction regulation to be effective.

Indonesia's teak furniture industry illustrates the potential of focusing on value addition. According to Purnomo, Guizol, and Mhutaman (2009), only $16 \%$ of teak furniture value accrues to the teak grower, which is $45 \%$ of domestic value addition. This implies that it should be possible to more than double the economic contribution from forestry per timber unit harvested, through processing improvements.

Source: Authors.

Certification of environmentally sustainable management offers a means for environmental values to be internalized in product marketing and pricing, and thus enables a form of payment for environmental services. Certification is common in plantation-based forestry, particularly in developed countries, and requires fewer new market arrangements than other means of payment for 
environmental services. However, forest certification is not yet practiced in Myanmar, as only initial steps have been taken toward the development of internationally recognized national standards for sustainable forest management, and accreditation bodies do not yet exist. Moreover, timber chains of custody currently do not make any distinction regarding timber source between timber from natural production forests, plantations or "conversion timber" from forest clearance for land-use change. Movement toward a modern chain of custody system wherein consumers can accurately appraise timber sources and can purchase certified timber with confidence will require substantial investment in national capacity. However, this is also an important area of investment, as it enables both economic benefits from access to premium timber markets, as well as sets incentives for sustainable management practices.

\section{CONCLUSIONS}

Myanmar's natural environment is under threat. That many environmental assets remain is largely a product of the absence of pressures associated with development, in a country isolated from major sources of foreign investment and trade for years. This means that there are likely to be far greater pressures on the country's resources in the coming years than those experienced to date, as foreign investment increases, trade expands, and the economy grows. Maintaining the environmental assets that Myanmar possesses will require proactive measures, not only to protect specific conservation areas, but to develop underlying conditions that are conducive to sustainable development.

Plantation expansion, infrastructure development, and timber exploitation all are likely to contribute to and accompany Myanmar's economic development. But they also have the potential to lead to large levels of deforestation, with attendant losses of carbon sequestration, watershed, and biodiversity services. Moreover, these effects can be exacerbated by many investments in roads that make forested areas more accessible. Similarly, improvements in fisheries harvesting methods and equipment will enable much higher and potentially unsustainable levels of fisheries catches, and increases in industrial output will be accompanied by greater levels of discharges of pollutants into air and water resources.

Developing a basis for balanced and sustainable development will require investment in institutions, regulations, and implementation capacity, as Myanmar is starting from a very low level in these areas. Not only are key regulations, procedures, and standards undefined, but there is little capability for monitoring compliance, and public awareness is insufficient for high levels of accountability regarding implementation.

Key measures needed to help ensure that Myanmar's development is sustainable include:

(i) Resolving fundamental incentives that drive environmental degradation, particularly open access resource management and implicit subsidization of environmental destruction through royalty charges on "conversion timber" that do not reflect full market values.

(ii) Reforming concession allocation processes, such that publicly available forest inventories precede allocation, high conservation value areas are excluded from concessions, and royalty payment compliance on conversion timber can be monitored.

(iii) Finalizing Environmental Impact Assessment regulations and procedures, such that meaningful assessments are ensured for projects with the potential for large impacts, that environmental management plans are robust, and that compliance is complete. 
(iv) Finalizing Environmental Quality Standards, pollutant discharge and waste stewardship regulations for protecting air, water, and ground resources.

(v) Building key analytical capacities within regulatory bodies for determination of sustainable forestry and fisheries harvesting levels, implementation of environmental regulatory processes, prioritization of conservation measures, and monitoring of environmental compliance.

(vi) Establishing clarity, stability, and accountability for regulatory decision making and environmental approvals, so that violations of approval procedures can be traced.

(vii) Helping to set the conditions for a robust and independent civil society to develop, which can help to monitor and ensure accountability for environmental policy enforcement.

(viii) Developing a chain of custody documentation requirements for the extractive resources, so that sources are clear, and to set the stage for the development of sustainable management certification.

There is currently considerable opportunity for the country to take advantage of its international attention and remaining environmental assets to attract support for measures that lead to effective protection and preservation of its ecological services. With the right investments, Myanmar can serve as an effective showcase for sustainable development. 


\section{REFERENCES}

Akaishi, F., M. Satake, M. Otaki, and N. Tominaga. 2006. Surface Water Quality and Information about the Environment Surrounding Inle Lake in Myanmar. Limnology. 7 (1). pp. 57-62.

Alliance for Zero Extinction (AZE). 2010 AZE Update. Washington, DC: American Bird Conservatory. http://www.zeroextinction.org

Asian Development Bank (ADB). 2012. Myanmar Energy Sector Initial Assessment. Manila.

2013. Southeast Asia Department Initial Sector Assessment, Strategy and Roadmap: Republic of the Union of Myanmar Agriculture, Natural Resources, and Environmental Sector. Manila. http://www.adb.org/sites/default/files/myanmar-energy-sector-assessment.pdf

Association of Southeast Asian Nations Secretariat (ASEAN). 2009. Fourth ASEAN State of the Environment Report. Jakarta, Indonesia. http://www.asean.org/resources/publications/aseanpublications/item/fourth-asean-state-of-the-environment-report-2009-2

2014. Myanmar Country Profile: Focus on Cities. ASEAN-German Technical Cooperation for Clean Air for Smaller Cities in the ASEAN Region. Bangkok.

Aye, S. L. 2005. Solid Waste Management Badly Needed in Myanmar. Policy Brief Series 2006-1. ISSN 1656-8 818. Los Baños, Philippines: Southeast Asian Regional Center for Graduate Study and Research in Agriculture.

Barbier, E. B., J. C. Burgess, and A. Grainger. 2010. The Forest Transition: Towards a More Comprehensive Theoretical Framework. Land-Use Policy. 27 (2). pp. 98-107.

Bathan-Baterina, G., K. Patdu, and M. Ajero. 2013. Urban Air Quality Management in Asia: Status and Trends [online]. Air Quality and Climate Change. 47 (4). pp. 32-7. http://search.informit.com .au/documentSummary; $\mathrm{dn}=601426229906787$;res=IELENG

BOBLME. 2011. Country Report on Pollution- Myanmar. Bay of Bengal Large Marine Ecosystem Project-2011-Ecology-13. http://www.boblme.org/documentRepository/BOBLME-2011Ecology-13.pdf

Booth S., and Pauly D (2011). Myanmar's Marine Capture Fisheries 1950-2008: Expansion from the Coast to Deep Waters. pp. 101-134. In S. Harper, D. O'Meara, S. Booth, D. Zeller, and D. Pauly, eds. Fisheries Catches from the Bay of Bengal Large Marine Ecosystem since 1950. Sea Around Us Project. www.seaaroundus.org

Burma Environment Working Group (BEWG). 2011. Burma's Environment: People, Problems, Policies. Chiang Mai, Thailand: Wanida Press.

Central Statistics Organization (CSO). 2012. Statistical Year Book 2011. Ministry of Planning and Economic Development. Nay Pyi Taw, Myanmar. 
Climatic Research Unit of University of East Anglia (CRU-UEA). 2014. Average Monthly Temperature and Rainfall for Myanmar from 1960-2009. World Bank. Climate Change Knowledge Portal. http://sdwebx.worldbank.org/climateportal/index.cfm?page=country_historical_climate \&ThisRegion=Asia\&ThisCCode=MMR\#

Culas, R., and D. Dutta. 2003. A Re-Examination of Causes of Deforestation and Environmental Kuznets Curve: Evidences from Latin America, Africa and Asia. School of Economics and Political Science Working Paper. Sydney, Australia: University of Sydney.

Emerson, J. W., A. Hsu, M. A. Levy, A. de Sherbinin, V. Mara, D. C. Esty, and M. Jaiteh. 2012. 2012 Environmental Performance Index and Pilot Trend Environmental Performance Index. New Haven: Yale Center for Environmental Law and Policy. http://www.epi.yale.edu

Ethnic Community Development Forum (ECDF). 2008. Biofuel by Decree: Unmasking Burma's BioEnergy Fiasco. http://burmalibrary.org/docs4/BiofuelbyDecree.pdf

Food and Agriculture Organization of the United Nations (FAO). 2010a. Global Forest Resources Assessment 2010. Country Report: Myanmar. FRA 2010/141. Rome.

2010b. Global Forest Resources Assessment 2010. FAO Forestry Paper 163. Rome.

2014. Global Forest Resources Assessment 2015. Country Report: Myanmar. Rome.

_,FAOSTAT. 2013. http://faostat.fao.org/site/630/default.aspx

,AQUASTAT. 2013. Fishery and Aquaculture Statistics. http://www.fao.org/nr/water/aquastat/ countries_regions/MMR/index.stm (accessed 23-25 October 2013).

Haggblade, S, D. Boughton, G. Denning, R. Kloeppinger-Todd, K. M. Cho, S. Wilson, L. C. Y. Wong, Z. Oo, T. M. Than, N. E. M. A. Wai, N. W. Win, and T. M. Sandar. 2013. A Strategic Agricultural Sector and Food Security Diagnostic for Myanmar. Working Paper draft for USAID/Burma by Michigan State University and the Myanmar Development Resource Institute's Center for Economic and Social Development. 14 March 2013. http://fsg.afre.msu.edu/Myanmar/ myanmar_agricultural_sector_and_food_security_diagnostic_report.pdf

Hannah, L., M. Ikegami, D. G. Hole, C. Seo, and S. H. M. Butchart. 2013. Global Climate Change Priorities for Biodiversity and Food Security. PLOS ONE. 8(8):e72590.

Hansen, M. C., P. V. Potapov, R. Moore, M. Hancher, S. A. Turubanova, A. Tyukavina, D. Thau, S. V. Stehman, S. J. Goetz, T. R. Loveland, A. Kommareddy, A. Egorov, L. Chini, C. O. Justice, and J. R. G. Townshend. 2013. High-Resolution Global Maps of 21st-Century Forest Cover Change. Science. 342 (6160). pp. 850-53.

Hsu, A., J. Emerson, M. Levy, A. de Sherbinin, L. Johnson, O. Malik, J. Schwartz, and M. Jaiteh. 2014. The 2014 Environmental Performance Index. New Haven, CT: Yale Center for Environmental Law and Policy. 
Institute for Global Environmental Strategies (IGES). 2012. Enabling Low-Carbon and ClimateResilient Development in Myanmar. Background paper prepared for Green Economy Green Growth Myanmar. Nay Pyi Taw, Myanmar. 13 November 2012.

International Union for Nature Conservation (IUCN). 2014. IUCN Red List. New Haven, CT: Yale University. www.iucnredlist.org/about/summary-statistics

Kaimowitz, D., and A. Angelsen. 1998. Economic Models of Tropical Deforestation: A Review. Bogor, Indonesia: Center for International Forestry Research.

Kreft, S., and D. Eckstein. 2013. Global Climate Risk Index 2014: Who Suffers Most from Extreme Weather Events and Weather-Related Loss Events in 2012 and 1993 to 2012? Germanwatch e.V. http://germanwatch.org/en/download/8551.pdf

Land Research Action Network (LRAN). 2012. Land not for Sale in Myanmar. http://www.landaction .org/spip.php?article666

McCoy, C. 2007. Turning Treasure into Tears: Mining, Dams and Deforestation in Shwegyin Township, Pegu Division, Burma. Washington, DC: Earthrights International.

Min Htut Yin. 2011. Environmental Sustainability, Issues and Strategies-Myanmar. Background Paper (14) for the Report on Development Policy Options, Myanmar-An Initiative of the UN Country Team in Myanmar.

Ministry of Agriculture and Irrigation of the Union of Myanmar (MOAI). 2010. Myanmar Country Report on Climate Change and Impacts on Agriculture and Food Security. http://www.foodsecuritylink.net/myanmar/index.php?option=com_remository\&ltemid $=13 \&$ func $=$ startdown\&id=84 (accessed 23 April 2014).

Ministry of Environmental Conservation and Forestry (MOECAF). 2010. Myanmar's First National Communication under the United Nations Framework Convention on Climate. Draft report.

2013. Fourth Governmental Meeting on Urban Air Quality in Asia and the Pacific - Myanmar Country Presentation Conducted by the Environmental Conservation Department, Ministry of Environmental Conservation and Forestry. Bangkok, Thailand. 6 February 2013.

2014. Fifth National Report to the Convention on Biological Diversity. Nay Pyi Taw, Myanmar.

Ministry of Livestock, Fisheries and Rural Development (MLFRD). 2013. Fishery Statistics 2013. Nay Pyi Taw, Myanmar.

National Commission for Environment al Affairs (NCEA) and United Nations Environment Programme (UNEP) Regional Resource Center for Asia and the Pacific. 2008. Myanmar National Environmental Performance Assessment Report. Bangkok, Thailand: GMS Environment Operations Center.

Online Burma/Myanmar Library. http://www.ibiblio.org/obl/show.php?cat=1189\&lo=\&sl= 
Oswell, A. H. 2010. The Big Cat Trade in Myanmar and Thailand: A Traffic Southeast Asia Report. Petaling Jaya, Malaysia: TRAFFIC. http://www.traffic.org/species-reports/traffic_species _mammals61.pdf

Purnomo, H., P. Guizol, and D. R. Mhutaman. 2009. Governing the Teak Furniture Business: A Global Value-Chain System Dynamic Modelling Approach. Environmental Modeling and Software. 24 (12). pp. 1391-401.

Rao, M., A. Rabinowitz, and S. T. Khaing. 2002. Status Review of the Protected-Area System in Myanmar, with Recommendations for Conservation Planning. Conservation Biology. 16 (2). pp. 360-68. $\quad$ http://onlinelibrary.wiley.com/doi/10.1046/j.1523-1739.2002.00219.x/abstract ;jsessionid=7658E3AFE2A982E84B5BC19E908BD0B5.f02t01

Talbott, K., J. Waugh, and D. Batson 2012. Sharing the Wealth: Burma's Post-Military Rule and Natural Resource Governance. Small Wars Journal. Bethesda, MD. http://smallwarsjournal.com/ $\mathrm{jrnl} /$ art/sharing-the-wealth-burma\%E2\%80\%99s-post-military-rule-and-natural-resourcegovernance

Than, M. M. 2005. Case Study 1: China's Developing Wood Industry and the Land Use Changes of Kachin State. Background paper for the FAO Forestry 2020 Outlook Study.

United Nations. COMTRADE Database. http://comtrade.un.org/

United Nations Environment Programme (UNEP). 2014. The UNEP Environmental Data Explorer. Compiled from United Nations Environment Programme/World Conservation Monitoring Center. United Nations Environment Programme. http://geodata.grid.unep.ch

United Nations Environment Programme (UNEP), Ministry of Environmental Conservation and Forestry (MOECAF), and Ministry of Transport. 2012. Myanmar's National Action Plan for Climate Change. Nay Pyi Taw, Myanmar.

United Nations Framework Convention on Climate Change (UNFCCC). 2013. GHG Emission Profiles for Non-Annex I Parties. Bonn, Germany. http://unfccc.int/files/ghg_data/ghg_data_unfccc/ ghg_profiles/application/msexcel/mmr_ghg_profile.xls

United Nations Office on Drugs and Crime (UNODC). 2013. Transnational Organized Crime in East Asia and the Pacific: A Threat Assessment. Vienna, Austria. https://www.unodc.org/ documents/toc/factsheets/TOC12_fs_environment_EN_HIRES.pdf

University of British Columbia Fisheries Centre and the PEW Charitable Trusts. 2011. The SEA Around Us Project. http://www.seaaroundus.org/ (accessed 3 July 2014).

von Thünen, J. H. 1826. Der Isolierte Staat in Beziehung auf Landschaft und Nationalökonomie. Translated by C. M. Wartenberg. 1966. Von Thünen's Isolated State. Oxford, UK: Pergamon Press.

Wildlife Conservation Society. 2013. Myanmar Biodiversity Conservation Investment Vision. Yangon, Myanmar. http://myanmar.wcs.org/ 
Woods, K. 2013a. Ceasefire Capitalism: Military-Private Partnerships, Resource Concessions, and Military-State Building in Burma-China borderlands. In N. L. Peluso, and C. Lund, eds. New Frontiers of Land Control. Oxon, UK: Routledge, Oxon.

- 2013b. Timber Trade Flows and Actors in Myanmar: The Political Economy of Myanmar's Timber Trade. Forest Trends. UK Department for International Development.

Woods, K., and K. Canby. 2011. Baseline Study 4 Myanmar: Overview of Forest Law Enforcement, Governance and Trade. Forest Trends for FLEGT Asia Regional Programme. Forest Trends Asia Regional Office, Beijing. http://www.forest-trends.org/documents/files/doc_3159.pdf

World Database on Protected Areas. http://www.wdpa.org/Statistics.aspx (accessed 3 February 2014).

World Health Organization (WHO) 2011. Urban Outdoor Air Pollution database. Geneva, Switzerland: WHO, Department of Public Health and Environment. http://www.who.int/phe (accessed 3 July 2014). 


\section{Achieving Environmental Sustainability in Myanmar}

Myanmar is at a critical crossroads. With many environmental assets, and industrial pressure only beginning to develop, it could effectively form policies and regulations that ensure sustainable growth and conservation of key natural resources. This paper aims to identify current and future environmental problems in Myanmar, the pressures underpinning them, and the policy measures that can manage them.

\section{About the Asian Development Bank}

ADB's vision is an Asia and Pacific region free of poverty. Its mission is to help its developing member countries reduce poverty and improve the quality of life of their people. Despite the region's many successes, it remains home to the majority of the world's poor. $A D B$ is committed to reducing poverty through inclusive economic growth, environmentally sustainable growth, and regional integration.

Based in Manila, ADB is owned by 67 members, including 48 from the region. Its main instruments for helping its developing member countries are policy dialogue, loans, equity investments, guarantees, grants, and technical assistance. 